\title{
Recent Development in Studies of Alternative Jet Fuel Combustion: Progress, Challenges, and Opportunities
}

\author{
Chi Zhang ${ }^{1}$, Xin Hui ${ }^{1,2}$, Yuzhen Lin ${ }^{1}$, and Chih-Jen Sung ${ }^{2}$ \\ ${ }^{1}$ National Key Laboratory of Science and Technology on Aero-Engine Aero-thermodynamics \\ School of Energy and Power Engineering \\ Beihang University \\ Beijing 100191, P. R. China \\ ${ }^{2}$ Department of Mechanical Engineering \\ University of Connecticut \\ Storrs, CT 06269, USA
}

\begin{abstract}
With the growing air transport demand and concerns about its environmental impacts, alternative jet fuels derived from non-conventional sources have become an important strategy for achieving a sustainable and green aviation. In the past ten years, governments around the world along with aviation industry have invested significant efforts into exploring all sorts of alternative jet fuels that can be used to power aircraft engines. Among all the alternative jet fuels explored, the aviation sector has agreed that hydrocarbon-based 'drop-in' replacement fuels, which are fully interchangeable and compatible with current conventional jet fuels, would be the best choice in the near future, as they can be used without any modifications to today's aircraft or fuel infrastructure. This paper reviews the current state of development of 'drop-in' alternative jet fuels including various Fisher-Tropsch synthetic jet fuels and bio-jet fuels. Recent advances in research activities on alternative jet fuels, including fuel property evaluations, combustor component tests, engine tests, and flight tests, are highlighted. Furthermore, basic research needs for understanding the combustion characteristics of alternative jet fuels are underlined and discussed by reviewing recent fundamental combustion studies on ignition, extinction, flame
\end{abstract}


propagation, emissions, and species evolution of various conventional and alternative jet fuels. Recognizing that the use of 'simpler' surrogate fuels to emulate the behavior of 'complex' alternative jet fuels is of fundamental and practical importance for the development of physicsbased models to enable quantitative emissions and performance predictions using combustion modeling, recent studies on surrogate formulation for alternative jet fuels are also reviewed and discussed. This review concludes with a brief discussion of future research directions.

Keywords: Alternative jet fuels; Synthetic jet fuels; Bio-jet fuels; Aviation emissions; Combustion characteristics; Jet fuel surrogates 


\section{Nomenclature}

ASTM American Standard for Testing and Materials

ATJ Alcohol To Jet

BPD Boiling Point Distribution

BTL Biomass To Liquid

CAAFI Commercial Aviation Alternative Fuels Initiative

CBTL Coal/Biomass To Liquid

CCS Carbon Capture and Sequestration

CHRJ Camelina-based HRJ

CTL Coal To Liquid

DCN Derived Cetane Number

FSJF Fully Synthetic Jet Fuel

FT Fisher-Tropsch

GTL Gas To Liquid

GHG Greenhouse Gases

HEFA Hydroprocessed Esters and Fatty Acids

HRJ Hydroprocessed Renewable Jet

IPK iso-Paraffinic Kerosene

LBO Lean Blowout

LTO Landing and Take-off

NTC Negative Temperature Coefficient

OEM Original Equipment Manufacturer

PM Particulate Matter

SMD Sauter Mean Diameter

SPK Synthetic Paraffinic Kerosene 


$\begin{array}{ll}\text { SSJF } & \text { Semi-Synthetic Jet Fuel } \\ \text { THRJ } & \text { Tallow-based HRJ } \\ \text { TSI } & \text { Threshold Sooting Index } \\ \text { UHC } & \text { Unburned Hydrocarbon }\end{array}$




\section{Introduction}

\subsection{Background}

Global energy demand will continue to increase in the next decade as the world has been reeling from the financial crisis and economic recession. In the transportation sector, air transport has been growing faster than any other transport mode in the recent years and is likely to continue growing rapidly in the future. Today, global aviation consumes about 5 million barrels of oil per day, accounting for about $5.8 \%$ of total oil consumption in the world [1]. The world jet fuel demand is projected to grow by $38 \%$ from 2008 to 2025 at a mean growth rate of $1.9 \%$ per year [2]. Air transport sector is currently the leading sector with significant growth in demand for oil, while the key driver for global jet fuel demand is led by emerging economies, such as China and India. The ever-increasing energy demand coupled with the finite fossil fuel reserve has put a great challenge on our society. The aviation industry and governments around the world have been developing rational strategies through non-conventional alternative jet fuels to accommodate the challenge.

The increasing aviation activity has elicited growing concern with regard to its impacts on environment and public health. Aircraft produces the same type of emissions as other ground transportation vehicles, including carbon monoxide $(\mathrm{CO})$, carbon dioxide $\left(\mathrm{CO}_{2}\right)$, water vapor $\left(\mathrm{H}_{2} \mathrm{O}\right)$, nitrogen oxides $\left(\mathrm{NO}_{\mathrm{x}}\right)$, sulfur oxides $\left(\mathrm{SO}_{\mathrm{x}}\right)$, unburned hydrocarbons (UHC), and particulate matters (PM). Depending on whether they occur near the ground or at altitude, aircraft emissions can be considered as local air quality pollutants or greenhouse gases (GHG), the latter are believed to be the primary cause for global climate change [3]. Aviation sector is relatively a small contributor to air pollutants compared to other sectors, it is estimated to account for $2-3 \%$ of total $\mathrm{CO}_{2}$ emissions and less than $3 \%$ of the transportation $\mathrm{NO}_{\mathrm{x}}$ emissions 

share of transport sources in the future. It has also been shown that high-altitude emissions near or in the stratosphere, where airliners frequently fly, can have significantly more impacts on the climate change compared to the ground-level emissions [5]. Aware of the challenges, the aviation community has invested much effort to tackle the issue. In 2009, International Air Transport Association (IATA) announced a three-step commitment for industry to achieve carbon-neutral growth: (1) $1.5 \%$ average annual improvement in fuel efficiency from 2010 to 2020; (2) carbon-neutral growth from 2020 onwards; (3) 50\% reduction in carbon emissions by 2050 as compared to the 2005 level [6]. More stringent standards and regulations on emissions are expected to push the industry towards a more sustainable and greener aviation.

In view of the above, society has been challenged to balance conflicting energy and environmental demands by decarbonizing our energy chain and finding clean and viable sources of fuel. Concerns about rising fuel price, energy supply, energy security, emissions, and climate change have called for a fresh look at the development and use of alternative jet fuels, which hold great potential for reducing aircraft emissions while expanding domestic energy sources. In the past decade, many alternative jet fuels, including synthetic fuels, bio-fuels, alcohol fuels, liquid hydrogen, liquid methane, etc., have been proposed and explored for aviation use. Aircraft original equipment manufacturers (OEMs) have been working closely with researchers to investigate the practicality of these alternative jet fuels in the near, mid, and far-term aircraft. Recently, the aviation community has agreed that 'drop-in' fuels are the most feasible choice for alternative jet fuels in the near future. A 'drop-in' jet fuel is a substitute for conventional jet fuel that is completely interchangeable and compatible with conventional jet fuel, and hence does not require any modifications to the current aircraft engine or fuel distribution system. The Federal 
Aviation Administration (FAA) has been working to enable the U.S. use of one billion gallons per year of alternative 'drop-in' fuels by 2018 [7]. Other countries as well as airliners have also been making enormous efforts for the development and commercialization of alternative 'drop-in' jet fuels. Therefore, the present paper focuses on the recent development and studies of alternative 'drop-in' jet fuels. It has to be pointed that alternative jet fuels discussed in this review are only referred to the hydrocarbon-based 'drop in' fuels, which have a similar energy content as the conventional jet fuels and can be either blended with or used as a total replacement of conventional jet fuels. Other alternative jet fuels such as liquid methane, liquid hydrogen, syngas, biogas, and oxygenated fuels are beyond the scope of the present paper.

\subsection{Conventional and alternative jet fuels}

Nowadays, the most used jet fuels are the kerosene-type fuels derived from petroleum. In U.S., Jet A is used in the commercial flights, while JP-8 is its counterpart for military use; JP-8 is similar to Jet A, but contains extra additives for corrosion and static protections. Jet A-1, which is widely used outside U.S., has similar composition as Jet A. The major difference between Jet A and Jet A-1 is that Jet A-1 has a lower freezing point $\left(-47^{\circ} \mathrm{C}\right)$, thereby making it more suitable for intercontinental flights. Some countries may have their own jet fuel grading. For example, Russia uses TS-1 and RT fuels for civil and military uses, respectively, while China uses RP-3 fuel for both civil and military use. Though there are some differences, TS-1, RT, and RP-3 are considered to be on a par with the western Jet A and Jet A-1 [8].

Compared to conventional jet fuels, alternative jet fuels can be derived from a variety of sources such as coal, oil shale, tar sand, plants, and animal fats. The compositions of alternative jet fuels can differ significantly based on their feedstocks and production process. Today, the two 
main industrial routes to alternative fuels in aviation are through (1) synthetic process of nature gas or coal (synthetic jet fuels) and (2) hydrotreating process of lipids (bio-jet fuels) [9].

Synthetic jet fuels are derived from fossil feedstocks such as coal, natural gas, and other hydrocarbons. Typically, the feedstocks are first gasified to produce a mixture of hydrogen and carbon monoxide known as synthesis gas. The synthesis gas is further converted into liquid hydrocarbons through Fisher-Tropsch (FT) process. The FT process is often termed as indirect liquefaction and fuels are often referred to as coal-to-liquid (CTL) and natural gas-to-liquid (GTL). However, some FT fuels that are derived from biomass (i.e. BTL - biomass-to-liquid) or coal/biomass (i.e. CBTL - coal/biomass-to-liquid) are not considered as 'synthetic', in the sense that they are not fossil-derived. Hence, BTL and CBTL fuels are generally referred to as nonsynthetic FT fuels, while the synthetic FT fuels are commonly termed as synthetic paraffinic kerosene (SPK).

There are many positive qualities associated with FT fuels. The most notable advantage is that they burn cleaner in aircraft engines. FT fuels generally produces approximately $2.4 \%$ less carbon dioxide, $50 \%-90 \%$ less particulate matter, and $100 \%$ less sulphur than conventional petroleum-based jet fuels [10]. FT fuels also have excellent low temperature properties and superior thermal stability that can improve high altitude operation and low temperature starting [10]. However, there are also some challenges and issues for using FT fuels. Although burning FT fuels produce less carbon emissions, the total life-cycle carbon emissions of synthetic FT fuels can be twice those of conventional jet fuels, if without involving any carbon capture and sequestration (CCS) technology during fuel production [11]. To reduce the life-cycle carbon emissions of FT fuels, FT plants need to further implement the necessary CCS technology, which, however, could significantly increase the fuel production cost [12]. Another issue with FT fuels 
is the potential failure of engine seals due to the lack of aromatic hydrocarbons. Aromatics have the desirous effect of causing engine seals to swell and prevent leakage [13]. To solve this problem, the fully-synthetic jet fuels (FSJF) are required to contain a minimum amount of aromatics to prevent seal failure. It is noted that there is no such requirement for the semisynthetic jet fuels (SSJF) since they are always blended with conventional jet fuels that already contain aromatics.

Bio-jet fuels are derived from biological matter (biomass) such as agricultural crops, trees, wood, plants, fibers, and animal wastes. Today, most bio-jet fuels are produced from plant oils (e.g., algae, camelina, jatropha, etc.) and animal fats (e.g., beef tallow) through hydroprocessing, a process that removes the chemically-bound oxygen and produces proper molecular weight components for jet fuels. Thus, these bio-derived fuels are often termed as hydroprocessed renewable jet (HRJ) or hydroprocessed esters and fatty acids (HEFA) fuels. One major advantage of HRJ fuels is that their feedstocks are renewable, which can reduce the energy reliance on the finite fossil fuel resources. In addition, unlike FT fuels, HRJ fuels can potentially be carbon neutral in a sense that the carbon emitted by burning a HRJ fuel can be offset by the carbon absorbed during the growing process of its feedstock. Though complete carbon neutrality can still be challenging in practice, HRJ fuels hold great potentials for reducing carbon emissions.

Figure 1 plots and compares the life-cycle GHG emissions for several FT, HRJ, and conventional jet fuels based on the data from PARTNER - Partnership for Air Transportation Noise and Emissions Reduction [11]. It can be seen that the life-cycle GHG emissions level of the FT CTL without CCS is $\sim 123 \%$ more than that of the baseline conventional jet fuel, while the FT CTL with CCS and FT GTL fuels have similar levels, which are about 11-15\% higher than the conventional jet fuel. In addition, all the HRJ fuels shown in Fig. 1 have substantial 

widely considered by the aviation industry to be one of the primary means to reduce its carbon footprint. Recently, Lokesh et al. [14] has predicted the "cradle-grave" carbon intensities of several bio-jet fuels using a life cycle GHC model. Their results revealed that bio-jet fuels derived from camelina, micro-algae, and jatropha deliver $70 \%, 58 \%$, and $64 \%$ of life cycle emissions savings, respectively, relative to Jet A-1. However, bio-jet fuels have some drawbacks that include low energy density, poor high-temperature thermal stability, storage instability, etc. For these reasons, bio-jet fuels need to be developed with technology that can address those issues and be able to tailor the resulting fuel for aircraft applications.

In general, the development and deployment of alternative jet fuels should depend on their sustainability that needs to be carefully assessed both economically and environmentally. The economical sustainability of alternative jet fuels needs to consider the costs of fuels, the implementation of new technologies, and the associated infrastructure changes, while the environmental sustainability mainly focuses on the issues of GHG emissions, air quality, land use, and water quality. In order to be sustainable, an alternative fuel has to be cost-competitive and maintain an ecological balance by avoiding depletion of nature resources. Though synthetic FT fuels are currently widely used, using natural gas and coal as their feedstocks has limited their capability for carbon reduction. However, the advantages of CTL and GTL fuels, including abundant reserves for feedstocks, low fuel price, domestic production, etc., still make them very attractive alternative jet fuels, especially in the coal-rich countries (e.g., U.S. and China) and the gas-rich countries (e.g., Russia). On the other hand, although non-synthetic FT fuels and bio-jet fuels that are derived from biomass have better carbon emission benefits compared to synthetic FT fuels, there have been concerns about their competition for farmland with food [15]. Since 

food uses, the industry needs to focus on the new-generation, sustainable biofuels that are derived from non-food crops. At the same time, the development of a new industry for bio-jet fuels has its risks and challenges, as the availability of bio-jet fuels in future depends on the large-scale production of biomass feedstocks, production technology and cost, world oil price, and emissions regulation. As the aviation community is striving to move toward to a sustainable and green aviation, the industry needs to ensure that the alternative fuels into which it invests will provide the hoped-for benefits (environmental, economic, etc.). More detailed discussions on the sustainability of alternative jet fuels can be found from a wide range of studies (e.g., [1621]).

\subsection{Strategies and global efforts for alternative jet fuels}

To achieve a sustainable and green aviation through alternative jet fuels, actions have been taken by governments and international aviation community. Early in 2003, the U.S. Department of Defense has launched Clean Fuels Initiative that includes two programs: Total Energy Development (TED) Program and Joint Battlefield Use Future Fuel (J-BUFF) Program. TED was aimed to catalyze commercial production of fuels from alternative energy resources, while JBUFF was designed to develop specifications for alternative jet fuels that enable a single fuel for the entire battle space [22]. In 2013, the U.S. Air Force (USAF) released its Energy Strategic Plan [23], in which USAF was committed to increase use of cost-competitive drop-in alternative aviation fuel blends for non-contingency operations to $50 \%$ of total consumption by 2025 .

In civil aviation, the Commercial Aviation Alternative Fuels Initiative (CAAFI) was formed in 2006 under the co-sponsorship of Aerospace Industries Association, Airports Council International-North America, Airlines for America, and U.S. Federal Aviation Administration 
(FAA). The CAAFI also consists of approximately 300 non-sponsor members and is a coalition of airlines, aircraft OMEs, energy producers, researchers, international participants, and government agencies. The CAAFI functions as a clearing house to facilitate the exchange of information and coordination of private-sector and government initiatives for the development and commercialization of alternative jet fuels [24]. In 2008, the European Union (EU) has launched a program of Alternative Fuels and Biofuels for Aircraft Development (ALFA-BIRD) that was aimed at developing the whole chain for alternative jet fuels. In 2011 , this R\&D program has adopted Sasol $\mathrm{FSJF}^{\circledR}$, a well characterized and certified fuel, as the reference fuel and tested several other alternative jet fuels. The test results were used to prepare the environmental and economic impact assessment that forms the basis for the elaboration of the future strategy for alternative jet fuels [25].

In 2009, twenty European and international organizations have launched a three year project, named as Sustainable Way for Alternative Fuels and Energy for Aviation (SWAFEA), to investigate the feasibility and impact of the use of alternative jet fuels. The final report of SWAFEA [26] was submitted to the European Commission to provide guidance to policy makers on aviation sustainability issues. This report pointed out the major economic issue for bio-jet fuels is their lack of competitiveness with conventional jet fuels, at least in the first decade of deployment; new technologies are required for more efficient processing pathways with higher yields and reduced costs. It was also suggested that the Commission explores the possibility of including bio-jet fuels in the EU Renewable Energy Directive, which sets a binding target of $20 \%$ share of total energy consumption from renewable sources and a $10 \%$ share of energy from renewable sources in transport by 2020 [27]. 
Being the fastest country in the growth of jet fuel demand, China has also launched its own alternative jet fuel initiative known as National Industrial Collaborative Innovation Alliance of Alternative Aviation Fuels in 2012. The initiative is a collaboration of several research institutes aiming for the development of alternative jet fuels as well as relevant certification processes and standards. In the same year, China Air Force and fuel producers have also started a program for the development of coal-derived jet fuels for both military and commercial use.

Other countries around the world have also started various initiatives and programs to boost the development and application of alternative jet fuels. More information and news with regard to alternative jet fuels can be found on the CAAFI website [28].

\subsection{Overview}

In a broad view of literature, many studies have already been devoted to the review of alternative jet fuels. For example, Gupta et al. [29] reviewed different kinds of bio-fuels for gas turbine applications. Law [30] reviewed the state of research on developing fuel options for nextgeneration chemical propulsion for aviation uses. Liu et al. [31] provided a technical review on the production processes of jet fuels including conventional/unconventional oiled-based process, FT process, and hydrotreating process. Chuck and Donnelly [32] discussed the compatibility of potential bio-derived fuels with Jet A-1. Kallio et al. [33] reviewed the existing technologies for renewable alternative jet fuel production. Hari et al. [34] reviewed the production routes for biojet fuels, including thermochemical process, hydroprocessing, biochemical process, and others. Murphy et al. [35] reviewed the biomass production for sustainable alternative jet fuels in Queensland, while Cremonez et al. [36] reviewed the current scenarios and prospects of bio-jet fuels in Brazil. Blakey et al. [37] provided a comprehensive review on the development of 'dropin' alternative jet fuels including fuel production pathways, life-cycle analysis, economic 
availability, flight tests, and engines tests on various combustion characteristics. In the present paper, we extend the work of Blakey et al. [37] with more recent progress in the development of 'drop-in' alternative fuels with focus on fuel properties and performance in various testing processes. In addition, we summarize fundamental studies on combustion characteristics of alternative jet fuels including fuel ignition, flame propagation, extinction, emissions, and combustion speciation. Finally, recent development on surrogate formation for alterative jet fuels is also highlighted, followed by a brief discussion of future fuel development and research directions.

\section{Alternative Jet Fuel Evaluations}

2.1. Path to alternative jet fuel readiness

To facilitate the development and deployment of alternative jet fuels, the CAAFI has developed a path to fuel readiness, also referred to as CAAFI communication tools [38]. The tools include fuel readiness level (FRL), FRL exit criteria, feedstock readiness level (FSRL), guidance for selling alternative jet fuels to airlines, and environmental progression. Moreover, the tools are designed to aid in the communication of both the necessary steps to be taken and the progress of alternative jet fuel projects.

In the process of alternative jet fuel development, FRL is commonly used to classify and track the progress on research, certification, and demonstration activities at different milestones, i.e. R\&D (FRL 1-5), Certification (FRL 6-7), and Business and Economics (FRL 8-9). In this chapter, we first introduce the jet fuel specification, and then focus on the property evaluations of alternative jet fuels in the $R \& D$ stage, followed by the combustor component, engine, and flight tests in the Certification stage. While the Business and Economics stage is outside the scope of 
this review, interested readers can refer to Refs. [39-41] for more information and discussions on this stage.

\subsection{Jet fuel specification}

Fuel specification is a list of standards by which the producers and users can identify and control the properties of fuel necessary for adequate and reliable performance. Two organizations have taken the leading roles in setting and maintaining specifications for jet fuels, namely the American Society for Testing and Material (ASTM) and the United Kingdom Ministry of Defense.

ASTM standard specification D1655 [42] defines specific types of jet fuels for civil use: Jet A and Jet A-1. It specifies that jet fuels shall be appropriately sampled and tested to examine their conformance to detailed requirements as to composition, volatility, fluidity, combustion, corrosions, thermal stability, contaminants, and additives [42]. In 2009, ASTM established new standard, ASTM D7566-09 [43], for aviation turbine fuels containing synthesized hydrocarbons produced from Fischer-Tropsch synthesis. In 2011, an annex with requirements for synthetic fuel components manufactured from HEFA was included in the new edition of ASTM D7566-11[44]. In the latest version of ASTM D7566-14c [45], the specification covers the manufacture of aviation turbine fuels that consist of conventional and synthetic blending components, and is intended to be used as a standard in describing the quality of aviation turbine fuels and synthetic blending components. In addition, the fuel certified by ASTM D7566 meets all the requirements of ASTM specification D1655 and can be regarded as D1655 fuel. This allows the new D7566 fuels to be seamlessly integrated into the current aircraft and infrastructures that are certificated for the D1655 fuels. 

additives [23]. This standard practice provides a framework for the certification of new jet fuels and new fuel additives for use in commercial and military aviation gas turbine engines. Figure 2 shows the fuel and additive approval process specified by ASTM D4054-09 [46]. In can be seen the certification process is composed of test program, OEM internal review, and specification change. The test program that includes specification properties, fit-for-purpose properties, component test, and engine test is intended to ensure the candidate fuel has no negative impact on engine safety, durability, or performance. However, it is unlikely that all the tests need to be performed, the OEMS should be consulted and will provide guidance on which tests are applicable. The test results are then reviewed by the respective OEM and FAA, additional data may be required based on the review. After the approval of a new fuel, if the OEM proposes changes to specification ASTM 1655, the proposed changes must be reviewed and balloted. The process is very rigorous and can go through several iterations before a change can be made to specification ASTM D1655. The practice ASTM 4054 was developed as a guide by the aviation gas-turbine engine OEMs with the support of ASTM international members, and the OEMs are solely responsible for approval of a fuel or an additive in their respective engines and airframes. It is also stated in the ASTM D7566 that synthetic fuels and blending components certified by this standard specification should have been evaluated and approved in accordance with the principles established in the standard practice of ASTM D4054.

Defense Standard 91-91 (DEF STAN 91-91) [47] issued on the behalf of Ministry of Defense by the UK Aviation Fuels Committee is another standard for aviation turbine fuel that defines the requirements for Jet A-1. Jet A-1 according to the DEF STAN 91-91 is very similar 
to Jet A-1 defined by the ASTM D1655 except for a small number of areas where DEF STAN 91-91 is more stringent. Similar to ASTM D7566, DEF STAN 91-91 in its Annex D also specifies the additional requirements for jet fuels that contain synthetic components. In addition, we note that Sasol SSJF ${ }^{\circledR}$ and Sasol FSJF ${ }^{\circledR}$ fuels have been approved in DEF STAN 91-91 [47].

There are also many other national jet fuel specifications. Most of them are based on either US (ASTM), UK (DEF STAN 91-91), or Russian (GOST 10227) specifications. There has been increasing moves to harmonize the small differences between the ASTM and DEF STAN as well as other national specifications.

As jet fuel supply becomes more complex with the development of alternative fuels, an international specification known as Aviation Fuel Quality Requirements for Jointly Operated Systems (AFQRJOS) Checklist has been proposed and recognized by a group of oil companies called Joint Inspection Group (JIG) [48]. This checklist is the combination of the most stringent requirements from ASTM and DEF STAN jet fuel specifications.

\subsection{Fuel property evaluation}

The starting point for assessing the feasibility of 'drop-in' alternative jet fuels is to evaluate their fuel properties and compare them with the known and well-characterized specifications of the conventional jet fuels. The proposed alternative jet fuel needs to be characterized with respect to its composition and physico-chemical properties to ensure its safety, reliability, and compatibility with today's airframe components and aero-engines. Further, the fuel property evaluation can provide insights into the fuel performance and its potential behavior during its implementation.

A conventional jet fuel, such as Jet A, is a mixture of hundreds of hydrocarbons from different molecular classes, including n-paraffins, iso-paraffins, cyclo-paraffins, and aromatics. 

fluidity, volatility, energy content, and combustion characteristics. These properties mainly depend on the bulk composition of the jet fuel and are weighted averages of all the individual components [22]. Specifically, the higher concentration of long n-paraffins can increase fuel energy content (per mass) and improve the combustion performance, but they can result in poorer low-temperature properties. While more iso-paraffins can improve fuel low-temperature properties, their reactivity is generally lower as compared to n-paraffins. On the other hand, cyclo-paraffins and aromatics can lead to higher fuel density, but they have lower resistance to flame extinction [49] and higher sooting propensity compared to normal and iso-paraffins [50].

Compared to conventional jet fuels, alternative jet fuels usually contain less molecular classes. Table 1 shows and compares the ASTM standards and fuel properties of Jet A, JP-8, and six representative alternative jet fuels, including Syntroleum S-8 ${ }^{\circledR}$, Shell GTL ${ }^{\circledR}$, Sasol IPK ${ }^{\circledR}$ (IsoParaffinic Kerosene), R-8, CHRJ (Camelina-based HRJ), and THRJ (Tallow-based HRJ). It can be seen that these alternative jet fuels are primarily composed of iso- and normal paraffins with a small fraction of cyclo-paraffins and negligible aromatics. Due to the different feedstocks and manufacturing processes, there can be significant differences among the alternative jet fuels in the spread of hydrocarbons as well as the ratio of normal to iso-paraffins and the presence of cyclo-paraffins.

Again, the differences in fuel composition can result in different fuel properties. For example, the freezing point is strongly dependent on the carbon number and the fraction of nparaffins. For the same carbon number, n-paraffins freeze at higher temperature than other compounds. As shown in Table 1, Sasol IPK $^{\circledR}$ has the lowest freezing point among all the fuels due to its much smaller amount of n-paraffins. The viscosity of fuel is more related to the 
molecular weight than the hydrocarbon class; Shell GTL ${ }^{\circledR}$ is the lightest fuel among all the alternative jet fuels and thus has the lowest viscosity.

To control the fuel quality, fuel specifications are used to confine the fuel properties within the acceptable range. In particular, alternative jet fuels should have a heat of combustion no less than $42.8 \mathrm{MJ} / \mathrm{kg}$, a flash point no less than $38^{\circ} \mathrm{C}$, and a freezing point not greater than $-47^{\circ} \mathrm{C}$ [54]. Most of requirements can be met by the alternative jet fuels that are listed in Table 1, except for density. Alternative jet fuels usually have lower densities than the minimum requirement of 775 $\mathrm{kg} / \mathrm{m}^{3}$ at $15^{\circ} \mathrm{C}$ specified in both ASTM D1655 and DEF STAN 91-91. The low density of alternative jet fuels is attributed to their small quantity of cyclo-paraffins and aromatics and can be a limiting factor in the blending ratio when blending with conventional jet fuels; it is therefore expected that the addition of synthetic aromatics would enable the use of fully-synthetic jet fuels $[55]$.

Fuel volatility is also an important fuel property that indicates the tendency of the fuel to vaporize and thus can further affect the ignition and combustion efficiency. Fuel volatility is expressed through the distillation curves as shown in Fig. 3 (data are from Refs. [13,51,56]). It is seen that S-8 has the highest boiling point distribution (BPD), while Shell GTL ${ }^{\circledR}$ and Sasol IPK ${ }^{\circledR}$ have the lowest BPDs. Other alternative jet fuels compared have similar BPDs as conventional Jet A and JP-8. In addition, the maximum and minimum of the distillation profiles based on the maximum and minimum values at each respective recovery point from the CRC world fuel survey [56] are also plotted in Fig. 3 as a reference. Although the alternative jet fuels can have different BPDs compared to the petroleum samples, they all meet the ASTM specification maximum limit [45]. 
Furthermore, the relatively flat BPDs of Shell GTL ${ }^{\circledR}$ and Sasol IPK ${ }^{\circledR}$ are primarily due to the lack of heavier fractions that would have come from the light distillate if available. Such BPDs can have effects on the results of the ignition and altitude relight tests. In general, although fuel volatility has no direct impact on the power or economy, less volatile fuels normally have higher heating values and thus the combustion performance is indirectly affected. Fuels with a higher front-end volatility (i.e. lower $10 \%$ distillation temperature) have a better starting and warm-up performance, while the deposit formation, wear, and exhaust smoke can be increased for the fuels with a higher back-end volatility (i.e. lower $90 \%$ distillation and end-point temperatures). As such, fuels that fail to meet distillation requirements usually cause increased pollutant emissions.

Thermal stability is usually improved for alternative jet fuels due to the absence of impurities, i.e. hetero-atoms, sulfur compounds, etc. However, the lack of organic acids or other polar compounds can decrease the lubricity of fuel. The JP-8 specification requires a maximum lubricity rating of 0.655 wear scar diameter. In addition, lubricity additive is generally required for FSJF to ensure adequate lubricity. The lack of aromatic compounds also can cause O-ring seals to shrink, harden, and fail. ASTM D7566 requires a minimum aromatic content of $8.0 \%$ by volume [45]. This limit is based on the operational experience to ensure that the required 'fit-forpurpose' properties (e.g., seal swell, lubricity, and material compatibility) are maintained for both semi-synthetic fuel blends and fully-synthetic jet fuels.

In summary, compared to conventional jet fuels, alternative jet fuels are less complex in compositions. They have excellent thermal stability and low emissions. The lack of aromatics in alternative jet fuels could cause issues in engine applications, such as material compatibility (elastomer swelling/shrinkage), tank gauging (density), and additive compatibility (solubility) 
[57]. However, these issues could be resolved and would not be a hindrance to the use of alternative jet fuels. Although most of the alternative jet fuels developed to date would likely meet the jet fuel specification standard, each of the alternative jet fuel can exhibit its own unique behavior. The differences in fuel properties are related to their unique characteristics imparted on the fuel by various feedstocks. Additional studies are necessary to better understand these characteristics to ensure that they are not significantly outside our current experience with the existing conventional jet fuels, especially considering the objective of drop-in replacement.

\subsection{Combustor component tests}

Though alternative jet fuels can meet the jet fuel specifications, engine OEMs still require to conduct a series of tests to assess various fuel performances for different combustor components. The component tests cover a wide range of fuel performances, such as fuel atomization, ignition, extinction, lean blowout (LBO), and emissions. Due to the variation of components from different engine OEMs, it is difficult to define a standard or criteria for the testing components and the associated conditions. As a result, combustor component tests are often conducted at OEMs' facilities using different components as appropriate. Table 2 lists recent combustor component tests reported in the literature for alternative jet fuels including both FT and HRJ fuels.

In the atomization tests, Williams [58] tested the Sasol FSFJ ${ }^{\circledR}$ using an auxiliary power units (APUs) atomizer. The test results showed that Sasol $\mathrm{FSJF}^{\circledR}$ had similar spray opening pressures, spray angles, and spray quality as Jet $\mathrm{A}$ at $-40^{\circ} \mathrm{C}$, but produced a smaller drop-size distribution that can provide a better cold starting [58]. Lin et al. [59] compared the atomization between a FT CTL and a conventional RP-3 jet fuel. A slightly smaller and more uniform droplet size distribution was also found in the spray of FT CTL at relatively lower fuel pressures [59]. 

pilot-scale pressure swirl nozzle, and found that GTL fuels have faster disintegration and dispersion of the droplets in the core region compared to Jet A-1. The smaller droplet size of Sasol FSFJ ${ }^{\circledR}$ and FT CTL tested in $[58,59]$ and faster disintegration and dispersion of GTL fuel droplets in [60] are believed to be caused by their lower viscosities compared to their counterpart conventional jet fuels. It should be noted that the viscosities of alternative jet fuels are not necessarily always lower than those of conventional jet fuels, as shown in Table 1. Sivakumar et al. [61] studied the atomization characteristics of a mixture of 90\% HRJ and 10\% aromatics from a simplex swirl atomizer. The results showed that the experimental measured SMD Of the tested biofuel spray agrees well with a previously reported correlation intended for conventional hydrocarbon fuel sprays from simplex swirl atomizers.

In the tests of ignition and altitude relight for alternative jet fuels, the results on Sasol FSJF ${ }^{\circledR}$ [62], FT GTL [63], and FT SPKs [64] showed that the tested alternative jet fuels had similar ignition performances as the conventional Jet A and Jet A-1; and it was also found in [64] that fuels with lower iso-to-normal ratio tended to have better ignition performance. Hermann et al. [65] studied and compared the ignition characteristics of a FT SPK and Jet A-1, and found that the tested FT SPK ignited under slightly richer conditions than Jet A-1. Note that the tested FT SPK in [65] has a higher flash point and a higher viscosity than Jet A-1. It was shown in [65] that the higher viscosity of the tested FT SPK resulted in larger droplet size which can lead to poorer fuel vaporization and thus inferior ignition performance. Lin et al. [59] demonstrated a leaner ignition limit for the tested FT CTL as compared to RP-3 at low liner pressure drop conditions, which was attributed to the lower viscosity of the tested FT CTL. In addition, Mosbach et al. [66] studied the chemiluminescence of $\mathrm{OH}$ and $\mathrm{CH}$ radicals in the transient process of flame ignition 
Burger et al. [67] studied the ignition and extinction behaviors of eight fuels, including conventional Jet A-1, SPKs, aromatic solvents, and pure compounds, in a representative aerocombustor. Their results showed that all the tested fuels have comparable ignition and extinction performance to conventional Jet A-1.

While the lean blowout tests of $[58,68]$ showed no significant differences between the tested alternative jet fuels and conventional ones, the results of [59] demonstrated a better LBO performance for the tested FT CTL than RP-3 at low liner pressure drop conditions, which could be caused by the different fuel distillation curves as suggested by the authors. Burger et al. [69] has systematically studied the lean blowout behavior of Sasol FSJF ${ }^{\circledR}$, SPK, Jet A-1, and other fuel blends in a heterogeneous laboratory combustor. The LBO results were correlated with fuel properties that included distillation profile, density, viscosity, flash point, and ignition delay. A strong correlation was found between the LBO limits and the fuel volatility, i.e. stability limits were reduced with decreasing volatility [69]. Density and viscosity were also found to have positive correlations in that a decrease of density and viscosity resulted in lower LBO limits and thus wider stability limits. Other fuel properties were found to have weak or no correlations with the observed LBO behavior [69].

Combustor emission tests are typically conducted to measure the pollutant emissions such as $\mathrm{CO}, \mathrm{NO}_{\mathrm{x}}$, unburned hydrocarbon (UHC), and soot (smoke). In the tests for alternative jet fuels, Biddle [70] found that Sasol $\mathrm{FSJF}^{\circledR}$ produced 4\% less $\mathrm{NO}_{\mathrm{x}}$ and $19 \%$ less $\mathrm{CO}$ than Jet A in the landing and takeoff (LTO) cycle, while UHC emissions were only reported in the idle conditions and were comparable for both fuels. The notable reduction in $\mathrm{CO}$ emissions was believed to be caused by the finer droplet size of Sasol FSJF ${ }^{\circledR}$ in the fuel spray, as shown in [58]. Hermann et 

ratios (F/A). The results of [65] showed that CO emission index for SPK was higher than that for Jet A-1 in the leaner conditions and was lower in the richer conditions; and $\mathrm{NO}_{\mathrm{x}}$ emission index for SPK was lower than that for Jet A-1 in all the tested conditions, except for rich conditions at high inlet air temperatures. Shouse et al. [68] compared the emissions of a FT GTL with those of JP-8 and found that CO emission of GTL was lower than that of JP-8 for all the tested F/A, while $\mathrm{NO}_{\mathrm{x}}$ emission of GTL was lower than that of JP-8 at leaner conditions, but higher at richer conditions. Other tests of $[59,71]$ showed no significant differences in $\mathrm{CO}$ and $\mathrm{NO}_{\mathrm{x}}$ emissions between the tested alternative and conventional jet fuels. Although differences are observed, the emissions of $\mathrm{CO}$ and $\mathrm{NO}_{\mathrm{x}}$ are generally in the same levels for both alternative and conventional jet fuels; the major difference in emissions with alternative jet fuels is in soot emission. In particular, the combustor emission tests of [65,68,70-72] all showed significant reductions in soot (smoke) emission when using alternative jet fuels. For example, Pucher et al. [71] showed that a $100 \%$ GTL and a 50/50 GTL/Jet A-1 blend had $83 \%$ and $65 \%$ reductions in smoke emission, respectively, compared to the base Jet A-1 fuel; and a 100\% HRJ had $96 \%$ reduction in smoke emission. Furthermore, the combustor deposits study in [72] showed a significant reduction in carbon and coke formation for using alternative jet fuels, as demonstrated in Fig. 4; it was found that the synthetic 100\% GTL and 50/50 GTL/Jet A-1 blend had 95\% and 64\% reductions in combustor deposits compared to Jet A-1, respectively. The substantial reduction in soot formation is, as expected, due to the lack of aromatic compounds in alternative jet fuels.

Based on the above-mentioned tests, it is seen that combustor performances can be dependent on the fuel properties. However, due to the variation of the testing components and operating conditions, the testing results can only be interpreted under their respective testing 
environments. To continuously improve the fuel certification process, standard testing methods are desirable in order to facilitate and streamline the testing practice. Though the current combustor components tests can be very different from each other, it can still be concluded from the testing results reported in the literature that the tested alternative jet fuels have no adverse effects on the combustor efficiency and emissions as compared to conventional jet fuels. Further, the soot emission can be drastically reduced when switching to or blending with alternative jet fuels due to their lack of aromatic components.

\subsection{Engine tests}

Ground engine tests are required upon completion of the combustor component tests in order to evaluate the fuel performance on the entire engine system. The purpose of the engine tests is to ensure the reliability and safety of alternative jet fuels and also to evaluate their pollutant emissions for all types of aero-engines such as turbofan, turboshaft, and APUs.

Recently, many engine tests have been conducted on various engines using conventional jet fuels and alternative FT and HRJ fuels, as well as their fuel blends. For example, Bester and Yates [73] conducted tests in a T63 gas turbine engine using FT SPK and Jet A-1; Bulzan et al. [74] measured gaseous and particulate emissions in a CFM56-2C1 engine on NASA's DC-8 aircraft using two FT fuels, JP-8, and their 50/50 blends; Timko et al. [75] measured the emissions in the PW 308 engine using FT and JP-8 fuels; Corporan and co-workers [76-78] studied the emission characteristics of FT, HRJ, and JP-8 fuels in various aircraft engines; Klingshirn et al. [79] evaluated the engine performance and emissions in a T63 turbine engine using HRJ and JP-8 fuels. Badami et al. [80] measured the emissions of Jet A, GTL, and a blend of 70\% Jet A and 30\% jatropha methyl ester in a small-scale SR-30 engine. Khandelwal et al. [81] compared emissions performance and vibration for Jet A-1 and two SPK fuels in a small gas 
turbine engine. Altaher et al. [82] measured UHC and carbonyl compounds of Jet A-1, GTL, HRJ, and HEFA from the exhaust gas of an APU gas turbine engine. Overall, the engine test results for alternative jet fuels in the above-mentioned studies showed no operational anomalies or detrimental effects on the engine performance compared to conventional jet fuels, while some improvements were observed. Specifically, about $1.2 \%$ improvement in thermal efficiency was observed in [73] for FT SPK compared to Jet A-1; the improvement was mostly attributed to the higher H/C ratio and lack of aromatics of the tested FT SPK. Also, engine emission profiles $[73,74,78-81]$ showed that the differences in $\mathrm{CO}$ and $\mathrm{NO}_{\mathrm{x}}$ emissions between conventional and alternative jet fuels were small, while some notable improvements in $\mathrm{CO}$ emissions were reported in [77]. All engine tests discussed herein showed dramatic reductions in soot and sulfur oxide emissions, which is consistent with combustor emission tests mentioned in the previous section. It was further found in $[75,76]$ that the tested FT fuels produced smaller soot particles than conventional JP-8. Moreover, despite the complex and varying engine combustor characteristics, a strong correlation between relative PM emissions and engine power was observed in [78]. It was suggested in [78] that this correlation can be potentially used to predict alternative fuel PM emissions. However, additional tests and inclusion of fuel chemistry are warranted to improve the robustness and validation of these correlations.

\subsection{Flight tests}

The flight test is the final testing step to demonstrate the use of a candidate jet fuel on a flying aircraft. As more alternative jet fuels have been developed, fight tests have been conducted more frequently for alternative jet fuels by many governments and commercial airlines.

Figure 5 summarizes the flight tests for alternative jet fuels since 2006. It is seen that the USAF has been playing a leading role in flight demonstrations of alternative jet fuels. 
Specifically, in 2006 USAF conducted a flight test on B-52 Stratofortress using a 50/50 blend of FT synthetic S-8 and JP-8, and the B-52 was the first aircraft approved by USAF of the use of alternative jet fuels [83]. Since then, a series of flight tests using FT synthetic fuel blends have been conducted by USAF on different military aircraft including C-17, F15, F22, etc. In 2010, USAF for the first time tested a blend of HRJ (CHRJ) and JP-8 on A-10 Thunderbolt. This test was a part of the effort that aims to evaluating candidate bio-jet fuels from various biomass materials with the least environmental impact. The CHRJ fuel blend has also been demonstrated later on other military aircraft by both USAF and US Navy. In 2012, USAF first flew an A-10 aircraft with a new fuel blend derived from alcohol (alcohol-to-jet, ATJ). In 2014, US Navy also conducted a test flight of F/A-18 Hornet fighter jet using an alcohol-based fuel blend. Both of the tests have proven that ATJ is a viable alternative jet fuel.

Commercial airlines, aircraft OEMs, fuel manufacturers, and other government agencies have also been active players in the flight tests of alternative jet fuels. In 2008, the Airbus A380 has become the first commercial aircraft to complete a flight using a FT GTL fuel blend. In the same year, Virgin Atlantic Airways conducted the first biofuel test with a GE CF6-powered Boeing 747-400 using a 20\% mix of biofuel composed of babassu oil and coconut oil, while Air New Zealand conducted a test flight using a Boeing 747-400 with a Rolls-Royce engine powered by a biofuel blend of standard jet fuel and kerosene derived from jatropha oil. In 2010, the South Africa fuel manufacturer Sasol has flown the world's first passenger aircraft using internationally approved 100\% synthetic jet fuel. In 2010, the Dutch military conducted the first flight test on the Ah-64 Apache helicopter using a bio-jet fuel blend that was derived from waste cooking oil. The first flight test using 100\% bio-jet fuel was conducted by National Researcher of Canada in 2012; the bio-jet fuel was derived from carinata oil and met jet fuel specifications without 


\section{Fundamental Combustion Properties}

As the development of alternative jet fuels has been gaining more momentum, a great effort has been devoted to the fundamental studies on alternative jet fuel characterization, mostly on the combustion characteristics in order to gain better understanding of alternative fuel chemistry. Since alternative jet fuels can vary significantly in composition as compared to conventional jet fuels, such fundamental combustion studies can provide insights into the impact of fuel properties on combustion and engine performance. The fundamental combustion properties of interest include ignition characteristics, flame properties, extinction limits, emissions, and combustion speciation. These combustion responses can be very sensitive to the fuel 
compositions and molecular structures, and are directly linked to the engine performances such as blowout, altitude relight, combustor efficiency, and emissions. Moreover, there are significant cost benefits that can be obtained by developing a more streamline combustion testing programs that includes these fundamental combustion studies [54]. The fundamental combustion data obtained can enable fuel manufacturers to improve their fuel developing process and screen out unacceptable fuels prior to expensive component and engine test. In addition, these fundamental combustion data can facilitate the development of alternative jet fuel surrogates and their chemical kinetic models that can be further used to enable quantitative emissions and performance predictions using combustion modeling.

\subsection{Autoignition delay time}

Autoignition delay time is an important parameter in the combustor design of aircraft engines. In engine combustion, rapid spontaneous ignition and the subsequent complete reaction of the fuel are required to achieve efficient combustion. Most autoignition studies have been conducted for homogeneous fuel/oxidizer mixtures in a closed device, such as shock tube and rapid compression machine (RCM). Autoignition delay time measured in such devices is ideally solely controlled by the chemical kinetics that depends on pressure and temperature histories of the given fuel/oxidizer mixture, and can vary widely for different fuels. The autoignition delay time

is typically defined as the time interval between the starting reference point, e.g., the end of compression in an RCM or the arrival of incident (or reflected) shock wave in a shock tube, and the onset of ignition. The major difference between shock tube and RCM is their testing/operating range; shock tube is more suitable in the high temperature range for short ignition delay measurements, while RCM is generally used in the low-to-intermediate temperature range for relatively longer ignition delay measurements. With the current 
development of RCM and shock tube facilities, their testing ranges can overlap with each other. However, discrepancies were observed between shock tube and RCM data in some overlapping ranges, and cautions need to be exercised by taking the facility effects into account when interpreting and comparing the results from shock tube and RCM $[85,86]$.

A number of studies have measured the autoignition delay times for conventional and alternative jet fuels. For example, Vasu et al. [87] measured the autoignition delay times of Jet A and JP-8 in a heated shock tube and in the temperature range of 715-1229 K and pressures of 17-51 atm; Kumar and Sung [88,89] measured the autoignition delay times in RCM for Jet A, JP-8, and S-8 in the low-to-intermediate temperature range of $615-1100 \mathrm{~K}$ at pressures of 7, 15, and 30 bar; Wang et al. [90] used a heated shock tube and measured the autoignition times of Jet A, S-8, Shell GTL ${ }^{\circledR}$, and Sasol IPK ${ }^{\circledR}$ in a wide temperature range of $651-1381 \mathrm{~K}$ at pressures varying from 8 to 39 atm; Allen et al. [91] measured the autoignition delay times of JP-8, CHRJ, and THRJ in a RCM in a low temperature range of $625-730 \mathrm{~K}$ at pressures of 5, 10, and $20 \mathrm{~atm}$. Zhu et al. [92] measured the ignition delay times of JP-8, HRJ, and FT fuels in the temperature range of $1047-1520 \mathrm{~K}$, equivalence ratios of $0.25-2.2$, and two pressure ranges of $2.07-8.27$ atm for fuel/air mixtures and 15.9-44.0 atm for fuel $/ 4 \% \mathrm{O}_{2} / \mathrm{Ar}$ mixtures. Valco et al. [93] measured the ignition delay times of JP-5, JP-8, two HRJ, and two FT fuels in RCM and shock tube in the temperature range of $625-1000 \mathrm{~K}$ and pressure of 20 atm. Figure 6 plots and compares the ignition delay times reported in the literature for various jet fuel/air mixtures at an equivalence ratio of 1.0 and a pressure of $20 \mathrm{~atm}$. It is seen that in high temperature regime (>900 K) both conventional jet fuel (Jet A) and FT SPK fuels (S-8, Shell GTL ${ }^{\circledR}$, and Sasol IPK ${ }^{\circledR}$ ) have similar ignition delay times. Below $900 \mathrm{~K}$, Jet A and FT SPK fuels start to differ from each other, but all the jet fuels in Fig. 6 show a slightly decreasing ignition delay time with decreasing 
temperature in a temperature range of approximately $750-900 \mathrm{~K}$, thereby exhibiting a negative temperature coefficient (NTC) response. It is further noted that the NTC regime is known to have strong pressure dependence and to shift to higher temperatures with increasing pressures. While the NTC regime may be relatively unimportant for the present aero-engines, this regime is expected to be of increased interest in advanced, next-generation engines of high efficiency and compression ratio.

In the low temperature regime $(<750 \mathrm{~K})$, there are notable differences in autoignition delay times between conventional jet fuels and alternative FT and HRJ fuels. It appears that in the lowto-intermediate temperature regime conventional jet fuels have longer autoignition delay times than alternative jet fuels, except for Sasol IPK ${ }^{\circledR}$. The relatively longer autoignition delay time of Sasol IPK $^{\circledR}$ is mainly attributed to its lack of reactive normal paraffins [90]. The different ignition propensities observed in the low-to-intermediate temperature regime indicate that there can be significant differences in the low-temperature chemistry, which is more specific and sensitive to fuel composition and structure as compared to the high-temperature chemistry. Recognizing that the NTC regime is expected to play an important role in future high-efficiency aero-engines, the low-to-intermediate temperature chemistry of alternative jet fuels merits further investigation. Other autoignition study of 50/50 (by volume) HRJ/JP-8 blends in the low temperature regime showed that the autoignition delay times of binary fuel blends are always bounded by the two baseline jet fuels [94].

\subsection{Derived cetane number}

Derived cetane number (DCN) is another parameter describing ignition characteristics in compression ignition engines. The higher DCN value means shorter ignition delay time and more likely the complete combustion of fuel charge in the combustor, which translates into a smoother 
running and better performing engine with more power and less emissions. Unlike the autoignition delay time measured for premixed, pre-vaporized mixtures in a homogenous environment, the ignition delay time measured for determining DCN is defined as the time interval from injection of the fuel to the start of combustion (hot ignition). The whole process includes fuel spraying, vaporization, fuel/air mixing, and ignition. Thus the DCN derived from this ignition delay time provides a direct measurement of ignition propensity in the compression engine conditions. There are two ASTM standard devices for DCN measurement: fuel ignition tester (FIT) [95] and ignition quality tester (IQT) [96]. Both devices utilize a constant volume combustion chamber $(0.60 \pm 0.03 \mathrm{~L}$ for FIT and $0.213 \pm 0.002 \mathrm{~L}$ for IQT) into which the fuel is injected; the chamber is initially kept at $2.40 \pm 0.02 \mathrm{MPa}$ and $510 \pm 50{ }^{\circ} \mathrm{C}$ for FIT and at $2.137 \pm 0.007 \mathrm{MPa}$ and $545 \pm 30{ }^{\circ} \mathrm{C}$ for IQT. An empirical correlation is used to calculate the DCN value based on the measured ignition delay time. Both FIT and IQT methods can produce fast, repeatable, and reliable DCN results in a range of about 30 to 65 , which is the typical range for kerosene fuels.

The DCN values of conventional and alternative jet fuels reported in various studies [53,57,97-99] are listed in Table 3. Jet A has a FIT DCN value of 49.35 determined by ASTM 7170 and an IQT DCN value of 47.1 determined by ASTM D6890, respectively. Though differences are observed between FIT and IQT results, both dataset are consistent in trend for all the jet fuels. From Table 3, it can also be seen that compared to Jet A and JP-8 all the alternative jet fuels have notably higher DCN values, except for Sasol IPK ${ }^{\circledR}$ which has significantly lower DCN values of $\sim 33$ and $\sim 31$ from FIT and IQT, respectively. The lower ignition propensity of Sasol IPK ${ }^{\circledR}$ is consistent with the fact that Sasol IPK ${ }^{\circledR}$ is primarily composed of less reactive branched alkanes. Although IPKs tend to have lower DCN values, they do not seem to impact on 
the engine performance. Therefore, there have been discussions within the community regarding the relevance of cetane number to gas turbine engine operation, whether there is a need to include ignition criteria for certification of alternative jet fuels, and if so, what the standard should be.

The DCNs of conventional and alternative jet fuel blends were also measured in [53]. Figure 7 plots the DCN values of S-8/Jet A and Sasol IPK ${ }^{\circledR} /$ Jet A blends as a function of Jet A volume fraction in the binary fuel blend. By definition, cetane number is a linear volumetric blend of the blending contribution of all the components in the fuels. Most models predict the blending cetane number based on linear combination of the cetane numbers of the components, even though there is evidence that the linear assumption is not always correct [100]. It can be seen from Fig. 7 that a fairly linear relationship is observed between DCN values and Jet A volume fraction in the binary fuel blend. The linear relationship is likely due to the relatively simple composition of alternative jet fuels. Similar linear trend has also been reported in IQT-DCN results for S-8/JP-8 and Shell GTL ${ }^{\circledR} /$ JP-8 blends [57].

\subsection{Laminar flame speed}

In the fundamental flame studies, laminar flame speed is one of the most important parameters of the combustible fuel/oxidizer mixture. It is defined as the velocity of a steady, one-dimensional, laminar propagation of a planar, adiabatic combustion wave into a uniform fuel/oxidizer mixture. The laminar flame speed embodies the fundamental information on the diffusivity, reactivity, and exothermicity of a given fuel/oxidizer mixture. On a practical level, laminar flame speed is related to the fuel burning rate in the combustor, thus affects the combustion efficiency and exhaust emissions. Over the years, several combustion facilities and techniques have been explored and made available for measuring laminar flame speed [101]. These measurements 
have employed either stationary burner flames held fixed by an upstream flow or propagating flames in open and closed chambers. Due to the inherent imperfection in these measuring techniques, most determinations of laminar flame speed require an extrapolation by eliminating the effects of heat loss, flow non-uniformity, or/and flame curvature.

Recently, Kumar et al. [102] measured the laminar flame speeds of conventional Jet A and alternative S-8 in a counterflow setup at preheat temperatures of 400,450 , and $470 \mathrm{~K}$ and a pressure of 1 atm. Mzé-Ahmed et al. [103] measured the laminar flame speeds of a CTL FSJF and Jet A-1 at a preheat temperature of $473 \mathrm{~K}$ and pressures of 1 and $3 \mathrm{~atm}$ in a conical flame burner. Also, Kick et al. [104] measured the laminar flame speeds of GTL and CTL FSJF at a preheat temperature of $473 \mathrm{~K}$ and atmospheric pressure in a conical flame burner. Using an explosion bomb, Vukadinovic et al. [105] measured the laminar flame speeds of Jet A-1, GTL, and GTL blend with $20 \%$ aromatics at preheat temperatures of 373,423 , and $473 \mathrm{~K}$ and pressures of 1, 2, and 4 atm. Furthermore, Hui et al. [53] measured the laminar flame speeds of Jet A, S-8, Sasol IPK ${ }^{\circledR}$, and CHRJ in a counterflow burner at preheat temperatures of 400 and $470 \mathrm{~K}$ and a pressure of $1 \mathrm{~atm}$. In a follow-up study using a high-pressure counterflow setup, Hui and Sung [106] reported the laminar flame speeds of Jet A and S-8 with a preheat temperature of $400 \mathrm{~K}$ in the pressure range of 1-3 atm. Munzar et al. [107] measured the laminar flame speeds of several blends of Jet A-1 and HRJ fuels at a preheat temperature of $400 \mathrm{~K}$ and atmospheric pressure.

Figure 8 plots the literature data of atmospheric laminar flame speeds of conventional and alternative jet fuels at a preheat temperature of about $473 \mathrm{~K}$. The laminar flame speed data were taken from four research groups [53,103-105] using different flame configurations and measurement techniques. Within each group, the measured laminar flames speeds of 
conventional and alternative jet fuels are quite similar, with the only exception for Jet A-1 at near stoichiometric conditions in [104]. Differences in the laminar flame speeds among the groups are mostly attributed to their different experimental techniques and the associated uncertainties in measurements and extrapolation methods. Though the laminar flame speed data are scattered, especially on the fuel rich side, all the data fall into a certain band of typical kerosene fuels. It is well known that the laminar flame speed is strongly dictated by the flame temperature through the Arrhenius kinetics, and the flame temperature is dependent on the heat of combustion. As shown in Table 1, alternative jet fuels have similar heat of combustion as conventional jet fuels, and hence both kinds of jet fuels are expected to have similar laminar flame speeds. Hui et al. [53] have also suggested that the laminar flame speed, controlled by the high temperature chemistry, is less sensitive to the fuel composition than ignition delay.

\subsection{Extinction strain rate}

Another important flame property is the flame extinction limit. The flame extinction can be induced by either incomplete reaction or the non-equidiffusion of heat and mass in conjunction with the flame stretch effect manifested by flow non-uniformity, flame curvature, and flow/flame unsteadiness. In the counterflow configuration, the extinction limit is usually captured by the strain rate of experienced by the flame at extinction. The extinction strain rate represents a kinetics-affected phenomenon and characterizes the interaction between a characteristic flame/flow time to a chemical reaction time. It is an important parameter to describe the flame stability and is directly linked to the engine blowout. The extinction strain rate can be measured both for premixed and non-premixed flames in a counterflow burner, and extinction is usually achieved by gradually increasing the flow velocity (hence the strain rate) until a flame blowout is 
observed. The maximum axial velocity gradient ahead of the flame just prior to the extinction is defined as the extinction strain rate.

Only a few studies have measured the extinction strain rates of conventional and alternative jet fuels. In the same study of laminar flame speeds, Hui et al. [53] measured the extinction strain rates of Jet A, S-8, Sasol IPK ${ }^{\circledR}$, and CHRJ in premixed flames at preheat temperatures of 400 and $470 \mathrm{~K}$ and a pressure of $1 \mathrm{~atm}$, as shown in Fig. 9. It needs to be pointed out that the oxidizer used in Ref. [53] was made of $86 \% \mathrm{~N}_{2}$ and $14 \% \mathrm{O}_{2}$ by mole in order to achieve extinction at moderate strain rates. The results in Fig. 9 show similar but slightly higher extinction strain rates for alternative jet fuels compared to conventional Jet A. Ji et al. [108] also measured the extinction strain rates of JP-8, S-8, Shell GTL ${ }^{\circledR}$, and R-8 using normal air in both premixed and non-premixed flames at $403 \mathrm{~K}$ preheat temperature and atmospheric pressure. Similar observation was made in [108] for both premixed and non-premixed flames that all the tested alternative jet fuels had similar extinction strain rates, which were higher than that of conventional JP-8. Dooley and co-workers $[52,98]$ measured extinction strain rates of Jet A and S-8 in non-premixed flames with fuel side temperature at $500 \mathrm{~K}$ and air side temperature at room temperature. The results of $[52,98]$ are plotted in Fig. 10, showing that alternative S-8 has notably higher extinction strain rates than conventional Jet A in the non-premixed flames.

Based on the above studies, it can be concluded that alternative jet fuels are more resistant to flame extinction than conventional jet fuels, especially in the non-premixed flame environments. The greater resistance is mostly due the absence of the less reactive aromatic components in the alternative jet fuels. The results also suggest that flame extinction limit is relatively more sensitive to the fuel composition than laminar flame speed. 


\subsection{Threshold sooting index}

The threshold sooting index (TSI) is defined in Eq. (1) by Calocte and Manos [109] as:

$$
\mathrm{TSI}=a\left(\frac{\text { Moelcular Weight }}{\text { Smoke point }}\right)+b,
$$

where the smoke point is the maximum smoke-free laminar non-premixed flame height (mm), molecular weight is in $\mathrm{g} / \mathrm{mol}$, and the coefficients of $a$ (mol.mm/g) and $b$ (dimensionless) are experimental constants. The TSI is a macro measure of the tendency of a fuel to form soot under diffusive/mixing limited conditions, and a useful parameter in predicting soot formation in practical combustors based on basic fuel compositions. If a correlation can be demonstrated between the TSI value measured in laboratory and the amount of soot formed in practical systems, then TSI can also be used in the fuel production process to define the desired fuel components from a given feedstocks. A few studies (e.g., $[110,111])$ have proposed correlations for jet fuels in order to use TSI to predict soot formation in aircraft engines.

Table 4 lists the TSI values of several conventional and alternative jet fuels available in the literature. As expected, since conventional Jet A and JP-8 include aromatic components in their compositions, they have the highest TSIs. Among the alternative jet fuels, Sasol IPK ${ }^{\circledR}$ has the highest TSI due to its heavily branched alkane compositions. It is further noted that the soot propensities for different hydrocarbon classes are generally, but not strictly, ranked as aromatics $>$ cyclic alkanes $>$ branched alkanes $>$ linear alkanes [109]. As Shell SPK ${ }^{\circledR}$ has the lowest TSI, it is most likely composed mainly of linear alkanes.

\subsection{Combustion speciation}

To further expand our combustion knowledge of alternative jet fuels with respect to their oxidation kinetics, speciation measurement is an important means to identify and quantify the important intermediate species and oxidation products. Speciation measurement is usually 
conducted in a well/jet stirred reactor or flow reactor for premixed flames. Such speciation data can be used to assess the fuel reactivity and to reveal possible pathways in the fuel oxidation process. Highlighted below are a number of studies that have been devoted to the combustion species measurements of alternative jet fuels.

Stouffer et al. [112] measured the oxidation products $\left(\mathrm{CO}_{2}, \mathrm{H}_{2} \mathrm{O}\right), \mathrm{O}_{2}$, and gaseous emissions (CO, UHC) of FT S-8 and JP-8 in a jet stirred reactor. It was found that gaseous emissions were similar for the two jet fuels and differences in the $\mathrm{H}_{2} \mathrm{O}$ and $\mathrm{CO}_{2}$ products appeared to be directly related to the $\mathrm{C} / \mathrm{H}$ ratio of the fuels. In addition, similar $\mathrm{NO}_{\mathrm{x}}$ emissions were found by Naik et al. [113] in counterflow premixed flames for S-8, Shell GTL ${ }^{\circledR}$, and R-8. Won et al. [99] measured $\mathrm{CO}, \mathrm{CO}_{2}, \mathrm{CH}_{2} \mathrm{O}, \mathrm{O}_{2}$, and $\mathrm{H}_{2} \mathrm{O}$ for Shell IPK ${ }^{\circledR}$, CHRJ, Sasol IPK ${ }^{\circledR}$, and JP-8 in a flow reactor. The results of [99] for $\mathrm{O}_{2}$ and $\mathrm{H}_{2} \mathrm{O}$ are shown in Fig. 11, based on which the relative fuel reactivity can be ranked as Shell $\mathrm{IPK}^{\circledR}>$ CHRJ $>$ JP-8 $>$ Sasol IPK $^{\circledR}$. Other species and heat release all showed similar trend in reactivity as Fig. 11. The lowest reactivity of Sasol IPK ${ }^{\circledR}$ is consistent with the lowest DCN values measured both in FIT and IQT.

Mzé-Ahmed and coworkers [103,114] also measured intermediate species and oxidation products of synthetic jet fuels and Jet A-1 in a jet stirred reactor. Their results showed strong similarity between alternative and conventional jet fuels, whereas some differences were observed mainly for some intermediate species, such as $\mathrm{CH}_{2} \mathrm{O}, \mathrm{CH}_{4}, \mathrm{C}_{2} \mathrm{H}_{4}$, and $\mathrm{C}_{3} \mathrm{H}_{6}$. Further, Dagaut et al. [115] studied the oxidation of a GTL fuel at 10 atm over the temperature range of $550-1150 \mathrm{~K}$ in a jet stirred reactor. It was found that the GTL oxidized rapidly, yielding saturated (mostly $\mathrm{CH}_{4}$ ) and unsaturated (olefins) hydrocarbon intermediates, as well as oxygenates (mainly $\mathrm{CH}_{2} \mathrm{O}$ and $\mathrm{CO}$ ) under the conditions studied. A comparison with Jet A-1 showed that both fuels oxidized similarly. 


\section{Surrogates for Alternative Jet Fuels}

\subsection{Surrogate fuel concept}

Computational engine modeling is an essential complementary tool for the engine manufacturers to test new engine components on computer before fabricating expensive prototypes. It also can be used to predict the engine efficiency and exhaust emissions for newly developed alternative jet fuels. The predictability of the numerical simulations relies on the fuel models of high-fidelity that can accurately describe the fuel properties and behaviors in different engine components and operating conditions. However, practical jet fuels are composed of hundreds of hydrocarbons from different molecular classes. The complexity of fuel composition makes it impossible for direct engine simulations even with today's computational power. A pragmatic way to overcome this difficulty is to use a surrogate fuel model. The underlying concept of a surrogate fuel is to mimic the behaviors of the target real fuel with manageable size that can be computed in a reasonable time frame. A surrogate is defined as a mixture of a limited number of hydrocarbons whose composition can be formulated in order to best emulate real fuel properties, such as physical properties, chemical properties, or even both. Edwards and Maurice [116] have defined two types of surrogates: physical surrogate and chemical surrogate. Physical surrogates are constructed to reproduce the thermophysical properties such as viscosity, thermal conductivity, energy density, distillation curves, surface tension, phase diagram etc. On the other hand, chemical surrogates are generally designed to have the same chemical-class composition and molecular weight as the target real fuels to reproduce selected aspects of combustion characteristics. A single component surrogate may be able to reproduce one or a few combustion characteristics of the target real fuel, but is not likely to capture a broader range of characteristics and certainly cannot reflect the carbon number distribution and molecular classes of real fuels. 
As a consequence, multi-component surrogates are usually favored for their broader applications. In addition, capturing some physical properties in chemical surrogates is also useful in combustion modeling where fuel atomization and evaporation are involved.

\subsection{Surrogate formulation}

Over the years, the surrogate strategy has received considerable attention for conventional jet fuels (e.g., $[52,97,116-120])$. Recognizing that surrogate models can be a powerful tool to the screening process by reducing the number of expensive full-scale rig and engine tests required to certify a candidate jet fuel, recent progress has been contributing to surrogate formation for alternative jet fuels. Table 5 summarizes recent developments of surrogates for alternative jet fuels $[98,113-115,121-124]$. It is seen that based on different intended applications for various alternative jet fuels, their surrogates can differ significantly in the compositions and validation targets, as well as the methodologies with which they were formulated.

Huber et al. [121] proposed a seven-component surrogate mixture to represent thermophysical properties of the synthetic S-8 fuel. An advanced distillation curve measurement [125] was employed to improve the volatility characteristics of the surrogate to better emulate the thermodynamic and transport properties of real S-8 fuel. In Huber et al. [121], the surrogate was formulated through two steps: (1) candidate component selection based on real fuel composition analysis and (2) composition determination through a multi-property regression that minimizes the differences between experimental and predicted thermophysical property data of S-8. The results of Huber et al. [121] showed that the proposed surrogate matched very well with S-8 in terms of distillation curve, and the density, speed of sound, thermal conductivity, and viscosity of the surrogate were also found to agree fairly well with those of S-8. Later, Huber et al. [122] further demonstrated the use of on-demand equations of state (EOS) to develop a 
surrogate model that describes the volatility behavior of a biomass-based fuel. Following the same step (1) described in [121], Huber et al. [122] first generated the EOS from the NIST ThermoData Engine [126], and subsequently used the EOS to determine the surrogate composition. A five-component surrogate was developed based on the on-demand EOS approach and was shown to be able to represent the distillation curve of S-8 within $0.1 \%$ accuracy [122].

Naik et al. [113] developed a detailed, high-temperature (above $1000 \mathrm{~K}$ ) chemical kinetic model for the proposed surrogates of two FT fuels (i.e. Shell GTL ${ }^{\circledR}$ and S-8) and one HRJ fuel (i.e. R-8). A software tool known as the surrogate blend optimizer (SBO) was employed to determine an optimum surrogate blend composition for the target real fuel by matching the userdefined performance targets which can include any combination of chemical composition, cetane number, $\mathrm{H} / \mathrm{C}$ molar ratio, lower heating value, density, and true boiling point curve. A genetic algorithm and a direction set algorithm were also implemented in SBO for global and local optimizations, respectively [113]. The two FT fuel surrogates were validated against laminar flame speeds, extinction strain rates, and $\mathrm{NO}_{\mathrm{x}}$ data measured in counterflow premixed flames. It was found in [113] that the two FT fuel surrogates with the detailed kinetic model were able to accurately predict these combustion properties of the real FT jet fuels.

Dooley et al. [98] proposed a two-component surrogate for S-8 to emulate its gas-phase chemical kinetic combustion phenomena. This S-8 surrogate was formulated on a specific basis through the sharing of $\mathrm{H} / \mathrm{C}$ molar ratio, DCN, TSI, and average molecular weight. The distinct chemical functionalities [97] that describe the production/consumption of intermediate species were also used in selecting candidate surrogate components that can produce the same distinct chemical functionalities as the real fuel components. The final composition of the surrogate in [98] was determined by matching certain combustion property targets, such as ignition delay 
time, laminar flame speed, extinction strain rate, etc. The two-component S-8 surrogate was further validated against species concentration data measured in a flow reactor, shock tube ignition delay data, and non-premixed flame extinction strain rates [98]. The good agreement between the surrogate and S-8 indicated that the underlying theory of distinct chemical functionalities, in addition to the combustion oriented metrics, is appropriate in surrogate fuel formulation [98].

Other studies on surrogate formulation for alternative jet fuels are also noted. Slavinskaya et al. [124] used an optimization method with a similar set of criteria as Naik et al. [113] to propose surrogates for synthetic GTL, while Mzé-Ahmed et al. [103] and Dagaut et al. [115] proposed their surrogates based on matching the oxidation species with those of the target alternative jet fuels. It is of interest to point out that both [103] and [115] suggested the inclusion of cycloparaffins and aromatics in their surrogate composition.

\section{Concluding Remarks and Future Directions}

To achieve a sustainable and green aviation, alternative jet fuels hold enormous potential in reducing the energy reliance on petroleum as well as aviation emissions. Initiatives have been developed around the globe to explore all sorts of alternative fuel sources and the associated technologies for the comprehensive use of alternative fuels in aviation. Alternative jet fuels can be derived from a wide variety of feedstocks such as coal, natural gas, and biomass. Due to the different feedstocks, each alternative jet fuel has its own unique behavior and must be certified through a series of rigorous evaluation and tests before commercialization. Many alternative jet fuels developed up to date have already been demonstrated successfully in both military and commercial aircraft. The results are encouraging in that they have shown no adverse effects on the combustor efficiency and gaseous emissions, while a significant reduction in soot emissions 
can be achieved compared to conventional jet fuels. In addition, beyond improvements in fuel efficiency, renewable jet fuels offer another means to reduce net carbon emissions.

As environmental and geopolitical concerns are driving demand for petroleum alternatives in aviation, it is also of importance to develop sustainability metrics for alternative jet fuels. The metrics include, but are not limited to, renewability, economic viability, environmental impact, energy security, etc. For commercial purpose in particular, alternative jet fuels need to be sustainable, able to be produced domestically and with diversity, cost-competitive, and capable of being produced in large quantities, as well as to have well-characterized life-cycle GHG footprint. Since life-cycle $\mathrm{CO}_{2}$ emissions can vary significantly, depending on the nature of the feedstocks, it is essential to carry out analysis of the life-cycle costs and the environmental side effects of potential alternatives. The preferred new jet fuels should be carbon-neutral and their production can avoid the potential conflicts in land use and energy-food-water systems such that the aggressive goal of industry $\mathrm{CO}_{2}$ emissions reduction roadmap can be met. It is also worth noting that the aviation sector will continue to undergo extensive development in alternative aviation fuels and to explore novel options beyond the current FT SPK and HRJ/HEFA.

Recent progress in the certification process for alternative jet fuels is reviewed in this paper. The certification process consists of extensive tests including initial physical property and composition tests, rig and component tests, engine tests, and flight tests. While this process has been codified in different countries, the approval process is under continuous refinement to reduce cost and improve the quality of the data obtained. Due to regulatory issues, the near-term goal for alternative jet fuel producers is to create a true 'drop-in replacement' fuel. Therefore, the premise for approving alternative jet fuels is that they must be fully interchangeable with current fuels in performance and handling without compromising flight safety. Although the similarity 
of SPK and HRJ fuels, which does not depend on feedstock, is expected to increase the fuel choice and flexibility, the fact that different processes can produce alternative jet fuels with dramatically different compositions leads to the current interest in continuous improvement of the fuel certification program. Recognizing that 'drop-in' petroleum replacements and blendstocks are the focus in near term and the applications of fully synthetic jet fuels are the mid-term goal, combustion 'rules and tools' for alternative jet fuels are needed to better understand the impact of fuel properties on combustor performance in order to ensure reliable operation of the engine.

Since alternative jet fuels can vary significantly in composition as compared to conventional jet fuels, substitution of conventional jet fuels with alternative jet fuels requires understanding of similarities and differences in fuel properties (both physical and chemical) and comprehensive knowledge of the combustion characteristics of alternative jet fuels. In addition, there are significant cost benefits in developing a more streamlined combustion testing program that includes fundamental characterization. Fundamental combustion datasets of interest include autoignition delay times, laminar flame speeds, extinction limits, and combustion species profiles, which are of direct relevance to ignition and altitude relight, flame propagation, lean blowout, and engine emissions, respectively. In this review, the fundamental combustion studies to date are highlighted and discussed. Some differences in combustion characteristics among alternative jet fuels and as compared to their conventional counterparts can be attributed to the differences in fuel composition. In general, the high temperature chemistry is relatively less sensitive to the fuel composition variations, while the low-to-intermediate temperature chemistry as well as the NTC response (if exists) can be more fuel specific. In view of the increasing importance of lowto-intermediate chemistry and potential NTC behavior in the next-generation aero-engines of 
high compression ratio, further chemical kinetic studies under the less-understood high-pressure, low-temperature, engine relevant conditions are strongly recommended. For combustion modeling of alternative jet fuels, several surrogate fuel models including both physical and chemical surrogates have been proposed and validated against real fuel properties (physical and combustion); all of them were found to be able to adequately predict the real fuel behaviors in their intended aspects. Further studies on alternative jet fuel combustion are warranted for a better understanding of fuel oxidation chemistry and comprehensive surrogate models with a wider range of predictability.

Finally, the importance of fundamental combustion research on alternative jet fuels cannot be over-emphasized and its goals for a sustainable and green aviation should include the development of viable technologies to assess the feasibility of alternative fuels in aviation applications as well as the advancement of validated physics-based models to enable quantitative emissions and performance predictions using combustion modeling. It is also of practical importance that fundamental combustion research can provide guidance for developing 'rules and tools' expediting certification and integration of new alternative jet fuels with petroleumderived products and current propulsion systems/infrastructure. Ultimately, fundamental combustion research and tests should facilitate and lead to the development of cost-effective screening of alternative jet fuels, the design for advancing existing and new aero-combustor concepts, and the integration of new non-petroleum-derived alternative fuel resources into the aviation sector. 


\section{Acknowledgements}

The work at Beijing University of Aeronautics and Astronautics was supported by the Project 51306010 of National Natural Science Foundation of China and China's Programme of Introducing Talents of Discipline to Universities - 111 Project under Grant No. B08009. The work at the University of Connecticut was supported as part of the Combustion Energy Frontier Research Center, an Energy Frontier Research Center funded by the US Department of Energy, Office of Science, Office of Basic Energy Sciences, under Award Number DE-SC0001198. The authors also would like thank Dr. Greg Pucher of the Royal Military College of Canada for providing Fig. 4. 


\section{References}

[1] The Outlook for Energy: A View to 2040. ExxonMobil; 2015. Retrieved April 15, 2015, from http://cdn.exxonmobil.com/ /media/Reports/Outlook For Energy/2015/2015-Outlook-forEnergy_print-resolution.pdf

[2] Chèze B, Gastineau P, Chevallier J. Forecasting world and regional aviation jet fuel demands to the mid-term (2025). Energy Policy 2011;39:5147-58.

[3] IPCC special report on renewable energy sources and climate change mitigation. 2011.

Retrieved April 15, 2015, from

http://www.uncclearn.org/sites/www.uncclearn.org/files/inventory/ipcc_summary_for_pm.pdf

[4] Aviation \& Emissions A Pimer. Federal Aviation Administration Office of Environment and Energy; 2005. Retrieved April 15, 2015 from

http://www.faa.gov/regulations_policies/policy_guidance/envir_policy/media/aeprimer.pdf

[5] Penner JE, Lister DH, Griggs DJ, Dokken DJ, McFarland M. Aviation and the Global Atmosphere: Cambridge University Press; 1999.

[6] Resolution on the implementation of the aviation "CNG2020" strategy. IATA (The International Air Transport Association); 2010. Retrieved April 15, 2015 from

http://www.iata.org/pressroom/pr/documents/agm69-resolution-cng2020.pdf

[7] Brown N. Alternative jet fuels - Feedstock development, processing and converion research \& regional supply and refining infrastructure. Federal Aviation Administration; 2012. Retrieved April 15, 2015 from

http://www.faa.gov/about/office_org/headquarters_offices/ang/offices/management/coe/media/pd f/ajfepMeeting/Alternative\%20Fuels\%20-\%20Part\%201.pdf 
[8] Edwards T. Advancements in gas turbine fuels from 1943 to 2005. J Eng Gas Turb Power 2007;129:13-20.

[9] Chiaramonti D, Prussi M, Buffi M, Tacconi D. Sustainable bio kerosene: Process routes and industrial demonstration activities in aviation biofuels. Appl Energ 2014;136:767-74

[10] Harrison WE. The drivers for alternative aviation fuels. Deparment of Defense Presentation; 2006. Retrieved April 15, 2015 from https://78f66f4de19f3837d6a9a7dfb2fe0ebed1dc53d3.googledrive.com/host/0B610OR9Z8sSrM GJ5WXJ4WmZBeWc/265_Harrison.pdf

[11] Stratton RW, Wong HM, Hileman JI. Life cycle greenhouse gas emissions from alternative jet fuels. Partnership of Air Transportation Noise and Emissions Reduction. Massachusetts Institute of Technology, Cambridge, MA; 2010. Retrieved April 15, 2015 from http://web.mit.edu/aeroastro/partner/reports/proj28/partner-proj28-2010-001.pdf [12] Carbon Dioxide Capture and Storage. Intergovernmental Panel on Climate Change (IPCC) Special Report, Cambridge University Press; 2005.

[13] Corporan E, Edwards T, Shafer L, DeWitt MJ, Klingshirn C, Zabarnick S, et al. Chemical, thermal stability, seal swell, and emissions studies of alternative jet fuels. Energ Fuel 2011;25:955-66.

[14] Lokesh K, Sethi V, Nikolaidis T, Goodger E, Nalianda D. Life cycle greenhouse gas analysis of biojet fuels with a technical investigation into their impact on jet engine performance. Biomass Bioenerg 2015;77:26-44.

[15] Hill J. Environmental costs and benefits of transportation biofuel production from food- and lignocellulose-based energy crops. A review. Agron Sustain Dev 2007;27:1-12. 
[16] Trivedi P, Olcay H, Staples MD, Withers MR, Malina R, Barrett SR. (2015). Energy return on investment for alternative jet fuels. Appl Energ 2015;141:167-74.

[17] Hileman JI and Stratton RW. Alternative jet fuel feasibility. Transport Policy 2014;34:52-62. [18] Staples MD, Malina R, Olcay H, Pearlson MN, Hileman JI, Boies A, Barrett SR. Lifecycle greenhouse gas footprint and minimum selling price of renewable diesel and jet fuel from fermentation and advanced fermentation production technologies. Energ Environ Sci 2014;7(5):1545-54.

[19] Staples MD, Olcay H, Malina R, Trivedi P, Pearlson MN, Strzepek K, Barrett SR. Water consumption footprint and land requirements of large-scale alternative diesel and jet fuel production. Environ Sci Technol 2013;47(21):12557-65.

[20] Atsonios K, Kougioumtzis M-A, Panopoulos KD, Kakaras E. Alternative thermochemical routes for aviation biofuels via alcohols synthesis: Process modeling, techno-economic assessment and comparison. Appl Energ 2015;138:346-66.

[21] Wolters F, Bank R, Schaefer M. Potential impact of renewable fuels and technological Innovations on global air traffic emissions development by 2050. ASME Turbo Expo, Düsseldor 2014. GT2014-25087.

[22] Lamprecht D. Fischer-Tropsch fuel for use by the U.S. military as battlefield-use fuel of the future. Energ Fuel 2007;21:1448-53.

[23] U.S. Air Force Energy Strategic Plan. U.S. Air Force; 2013. Retrieved April 15, 2015 from http://www.safie.hq.af.mil/shared/media/document/AFD-130325-124.pdf

[24] Commercial Aviation Alternative Fuels Initiative. International Civil Aviation Organization. Retrieved April 15, 2015 from

http://www.icao.int/environmental-protection/GFAAF/Pages/Project.aspx ?ProjectID=10 
[25] ALFA-BIRD:Alternative fuels and biofuels for aircraft development overview of main results. Frankfurt Airport, Germany: 2nd AirTN Forum; 2012. Retrieved April 15, 2015 from http://www.airtn.eu/downloads/airtn-alfabird-web-sent-2012.pdf

[26] Sustainable Way for Alternative Fuels and Energy in Aviation. SWAFEA Final Report; 2011. Retrieved April 15, 2015 from

http://www.icao.int/environmentalprotection/GFAAF/Documents/SW_WP9_D.9.1\%20Final\%20report_released\%20July2011.pdf [27] Directive 2009/28/EC of the Eeuropean Parliament and of the Council of 23 April 2009 on the promotion of the use of energy from renewable sources and amending and subsequently repealing Directives 2001/77/EC and 2003/30/EC. 2009. Retrieved April 15, 2015 from http://faolex.fao.org/docs/pdf/eur88009.pdf [28] Commercial Aviation Atlernative Fuels Initiative. Retrieved April 15, 2015 from http://www.caafi.org/news/NewsArchive.aspx [29] Gupta KK, Rehman A, Sarviya RM. Bio-fuels for the gas turbine: A review. Renew Sust Energ Rev 2010;14:2946-55.

[30] Law CK. Fuel options for next-generation chemical propulsion. AIAA Journal 2012;50:1936.

[31] Liu G, Yan B, Chen G. Technical review on jet fuel production. Renew Sust Energ Rev 2013;25:59-70.

[32] Chuck CJ and Donnelly J. The compatibility of potential bioderived fuels with Jet A-1 aviation kerosene. Appl Energ 2014;118:83-91.

[33] Kallio P, Pásztor A, Akhtar MK, Jones PR. Renewable jet fuel. Curr Opin Biotech 2014;26:50-55. 
[34] Hari TK, Yaakob Z, Binitha NN. Aviation biofuel from renewable resources: Routes, opportunities and challenges. Renew Sust Energ Rev 2015;42:1234-44.

[35] Murphy HT, O'Connell DA, Raison RJ, Warden AC, Booth TH, Herr A, et al. Biomass production for sustainable aviation fuels: a regional case study in Queensland. Renew Sust Energ Rev 2015;44:738-50.

[36] Cremonez PA, Feroldi M, de Araújo AV, Borges MN, Meier TW, Feiden A, (2015). Biofuels in Brazilian aviation: Current scenario and prospects. Renew Sust Energ Rev 2015;43:1063-72.

[37] Blakey S, Rye L, Wilson CW. Aviation gas turbine alternative fuels: A review. Pro Combust Inst 2011;33:2863-85.

[38] Path to Alternative Jet Fuel Readiness. CAAFI; 2011. Retrieved April 15, 2015 from http://www.caafi.org/information/pdf/Path_to_Aviation_Alternative_Fuel_Readiness_posted_20 11_12.pdf

[39] Withers MR, Malina R, Gilmore CK, Gibbs JM, Trigg C, Wolfe PJ, et al. Economic and environmental assessment of liquefied natural gas as a supplemental aircraft fuel. Prog Aerosp Sci 2014;66:17-36.

[40] Christensen D, Peineke C, Tamboer B, Hagenzieker R, Druten Lv. Business Case \& Implementation Strategies. European Commission's Directorate General for Mobility and Transport; 2011.

[41] Winchester N, McConnachie D, Wollersheim C, Waitz IA. Economic and emissions impacts of renewable fuel goals for aviation in the US. Transport Res A-Pol 2013;58:116-28.

[42] Standard Specification for Aviation Turbine Fuels. ASTM D1655-15. Retrieved April 15, 2015 from http://www.astm.org/Standards/D1655.htm 
[43]Standard Specification for Aviation Turbine Fuel Containing Synthesized Hydrocarbons. ASTM D7566-09. Retrieved April 15, 2015 from

http://www.astm.org/DATABASE.CART/HISTORICAL/D7566-09.htm

[44] Standard Specification for Aviation Turbine Fuel Containing Synthesized Hydrocarbons. ASTM D7566-11. Retrieved April 15, 2015 from http://www.astm.org/DATABASE.CART/HISTORICAL/D7566-11.htm

[45] Standard Specification for Aviation Turbine Fuel Containing Synthesized Hydrocarbons. ASTM D7566-14c. Retrieved April 15, 2015 from http://www.astm.org/Standards/D7566.htm [46] Standard Practice for Qualification and Approval of New Aviation Turbine Fuels and Fuel Additives. ASTM D4054-09. Retrieved April 15, 2015 from http://www.astm.org/DATABASE.CART/HISTORICAL/D4054-09.htm [47] Defence Standard 91-91, Issue 7-Turbine Fuel, Kerosine Type, Jet A-1. NATO Code: F-35. Joint Service Designation: AVTUR. Technical Report, Ministry of Defence, 2011. Retrieved April 15, 2015 from

http://www.seta-analytics.com/documents/Defstan_91-91_R7.pdf

[48] Aviation Fuel Quality Requirements for Jointly Operated Systems (AFQRJOS). Joint Inspection Group; 2012. Retrieved April 15, 2015 from http://www.jigonline.com/wp-content/uploads/2012/05/Bulletin-51-AFQRJOS-Issue-26-May2012.pdf

[49] Holley AT, Dong Y, Andac MG, Egolfopoulos FN, Edwards T. Ignition and extinction of non-premixed flames of single-component liquid hydrocarbons, jet fuels, and their surrogates. Pro Combust Inst 2007;31:1205-13. 
[50] Nakakita K, Akihama K, Weissman W, Farrell J. Effect of the hydrocarbon molecular structure in diesel fuel on the in-cylinder soot formation and exhaust emissions. Int J Engine Res 2005;6:187-205.

[51] Rahmes TF, Kinder JD, Henry TM, Crenfeldt G, LeDuc GF, Zombanakis GP, et al. Sustainable bio-derived synthetic paraffinic kerosene (Bio-SPK) jet fuel flights and engine tests program results. 9th AIAA Aviation Technology, Integration, and Operations Conference, South Carolina 2009. AIAA2009-7002.

[52] Dooley S, Won SH, Chaos M, Heyne J, Ju Y, Dryer FL, et al. A jet fuel surrogate formulated by real fuel properties. Combust Flame 2010;157:2333-9.

[53] Hui X, Kumar K, Sung CJ, Edwards T, Gardner D. Experimental studies on the combustion characteristics of alternative jet fuels. Fuel 2012;98:176-82.

[54] Edwards T, Moses C, Dryer F. Evaluation of combustion performance of alternative aviation fuels. 46th AIAA/ASME/SAE/ASEE Joint Propulsion Conference \& Exhibit, Nashville 2010. AIAA2010-7155.

[55] Moses CA. Development of the protocol for acceptance of synthetic fuels under commercial specification. Coordinating Research Coucil Report AV-2-04, Alpharetta, GA September 2007. Retrieved April 15, 2015 from http://crcao.com/reports/recentstudies2007/AV-02-04/AV-2-04\%20Final\%20Report\%20\%20FINAL2\%20March\%202-2008.pdf

[56] Hadaller O and Johnson J. World fuel sampling program. Coordinating Research Council, Inc, CRC Report; 2006. Retrieved April 15, 2015 from http://mycommittees.api.org/rasa/jfm/Shared\%20Documents/Resource\%20Materials/Compositio n\%20data/World\%20Fuel\%20Sampling\%20Program\%202006\%20Report.pdf 
[57] Bessee GB, Hutzler SA, Wilson GR. Propulsion and Power Rapid Response Research and Development (R\&D) Support. Delivery Order 0011: Analysis of Synthetic Aviation Fuels. DTIC Document; 2011. Retrieved April 15, 2015 from http://www.dtic.mil/cgi-bin/GetTRDoc?Location=U2\&doc=GetTRDoc.pdf\&AD=ADA547232 [58] Williams R. Final report evaluation of sasol fully synthetic jet fuel for approval for use as Jet A-1 fuel. Honeywell Aerospace; 2007. Report No. 21-13781.

[59] Lin Y, Lin Y, Zhang C, Xu Q, Sung CJ, Liu G. Evaluation of combustion performance of a coal-derived synthetic jet fuel. ASME Turbo Expo, Copenhagen 2012. GT2012-68604.

[60] Kannaiyan K and Sadr R. Experimental investigation of spray characteristics of alternative aviation fuels. Energ Convers Manage 2014;88:1060-9.

[61] Sivakumar D, Vankeswaram SK, Sakthikumar R, Raghunandan BN. Analysis on the atomization characteristics of aviation biofuel discharging from simplex swirl atomizer. Int $\mathbf{J}$ Multiphas Flow 2015;72:88-96.

[62] Herman F. Cold day ignition and altitude relight testing of SASOL fully synthetic aviation kerosene -- External report to Southwest Research Institute, Rolls-Royce PLC 2007. Report No DNS.126274.

[63] Rye L and Wilson CW. The influence of alternative fuel composition on gas turbine ignition performance. Fuel 2012;96:277-83.

[64] Fyffe D, Moran J, Kannaiyan K, Al-Sharshani A, Sadr R. Effect of GTL-like jet fuel composition on gt engine altitude ignition performance: Part I--Combustor operability. ASME Turbo Expo, Vancouver 2011. GT2011-45487. 
[65] Hermann F, Hedemalm P, Orbay R, Gabrielsson R, Klingmann J. Comparison of combustion properties between a synthetic jet fuel and conventional Jet A-1. ASME Turbo Expo, Nevada 2005. GT2005-68540.

[66] Mosbach T, Gebel GC, Clercq PL, Sadr R, Kannaiyan K, Al-Sharshani A. Investigation of GTL-like jet fuel composition on GT engine altitude ignition and combustion performance: Part II--Detailed Diagnostics. ASME Turbo Expo, Vancouver 2011. GT2011-45510.

[67] Burger V, Mosbach T, Yates A, Gunasekaran B. Fuel influence on targeted gas turbine combustion properties part II: Detailed results. ASME Turbo Expo, Düsseldorf 2014. GT201425105 .

[68] Shouse DT, Neuroth C, Hendricks RC, Lynch A, Frayne C, Stutrud JS, et al. Alternatefueled combustor-sector performance: Part A: Combustor performance Part B: Combustor emissions. 2010. ISROMAC13-2010-49.

[69] Burger V, Yates A, Viljoen C. Influence of fuel physical properties and reaction rate on threshold heterogeneous gas turbine combustion. ASME Turbo Expo, Copenhagen 2012. GT2012-68153.

[70] Biddle T. Pratt \& Whitney emissions test to determine the effect of sasol fully synthetic jet-a fuel on the emissions of a commercial combustor. Southwest Research Institute; 2007.

[71] Pucher G, Poitras P, Allan W, LaViolette M. Emissions from a gas turbine sector rig operated with synthetic aviation and biodiesel fuel. J Eng Gas Turb Power 2011;133:111502.

[72] Pucher G, Allan W, Poitras P. Characteristics of deposits in gas turbine combustion chambers using synthetic and conventional jet fuels. J Eng Gas Turb Power 2013;135:071502. 
[73] Bester N, Yates A. Assessment of the operational performance of Fischer-Tropsch syntheticparaffinic kerosene in a T63 gas turbine compared to conventional Jet A-1 fuel. ASME Turbo Expo, Orlando 2009. GT2009-60333.

[74] Bulzan D, Anderson B, Wey C, Howard R, Winstead E, Beyersdorf A, et al. Gaseous and particulate emissions results of the NASA alternative aviation fuel experiment (AAFEX). ASME Turbo Expo, Glasgow 2010. GT2010-23524.

[75] Timko MT, Yu Z, Onasch TB, Wong HW, Miake-Lye RC, Beyersdorf AJ, et al. Particulate emissions of gas turbine engine combustion of a Fischer-Tropsch synthetic fuel. Energ Fuel 2010;24:5883-96.

[76] Corporan E, DeWitt MJ, Klingshirn CD, Striebich R, Cheng MD. Emissions characteristics of military helicopter engines with JP-8 and Fischer-Tropsch fuels. J Propul Power 2010;26:31724.

[77] Corporan E, DeWitt MJ, Klingshirn CD, Anneken D. Alternative fuels tests on a C-17 aircraft: Emissions characteristics. Air Force Research Laboratory; 2010. Retrieved April 15, 2015 from http://www.dtic.mil/dtic/tr/fulltext/u2/a536842.pdf

[78] Corporan E, DeWitt MJ, Klingshirn CD, Anneken D, Streibich R, Shafer L. Comparisons of emissions characteristics of several turbine engines burning Fischer-Tropsch and hydroprocessed esters and fatty acids alternative jet fuels. ASME Turbo Expo, Copenhagen 2012. GT201268656.

[79] Klingshirn CD, DeWitt M, Striebich R, Anneken D, Shafer L, Corporan E, et al. Hydroprocessed renewable jet fuel evaluation, performance, and emissions in a T63 turbine engine. J Eng Gas Turb Power 2012;134:051506. 
[80] Badami M, Nuccio P, Pastrone D, Signoretto A. Performance of a small-scale turbojet engine fed with traditional and alternative fuels. Energ Convers Manage 2014;82:219-28.

[81] Khandelwal B, Roy S, Lord C, Blakey S. Comparison of vibrations and emissions of conventional jet fuel with stressed $100 \%$ SPK and fully formulated synthetic jet fuel. Aerospace 2014;1(2):52-66.

[82] Altaher MA, Li H, Blakey S, Chung W. NMHC and VOC speciation of the exhaust gas from a gas turbine engine using alternative, renewable and conventional Jet A-1 aviation fuels. ASME Turbo Expo, Düsseldorf 2014. GT2014-25445.

[83] Fritschen JM. U.S. air force Fisher-Tropsch alternative fuel development: six-step demonstration. US Air Force T\&E Days. Destin, Florida 2007.

[84] ACCESS II: A team efffort by NASA, DLR, NRC. 2014. Retrieved April 15, 2015 from http://www.nasa.gov/centers/armstrong/Features/ACCESSIIateameffort.html

[85] Petersen EL, Lamnaouer M, Vries J, Curran H, Simmie J, Fikri M, et al. Discrepancies between shock tube and rapid compression machine ignition at low temperatures and high pressures. Shock Waves 2009;739-44.

[86] Sung CJ and Curran HJ. Using rapid compression machines for chemical kinetics studies. Prog Energ Combust 2014;44:1-18 .

[87] Vasu SS, Davidson DF, Hanson RK. Jet fuel ignition delay times: Shock tube experiments over wide conditions and surrogate model predictions. Combust Flame 2008;152:125-43.

[88] Kumar K and Sung CJ. A comparative experimental study of the autoignition characteristics of alternative and conventional jet fuel/oxidizer mixtures. Fuel 2010;89:2853-63.

[89] Kumar K and Sung CJ. An experimental study of the autoignition characteristics of conventional jet fuel/oxidizer mixtures: Jet-A and JP-8. Combust Flame 2010;157:676-85. 
[90] Wang H and Oehlschlaeger MA. Autoignition studies of conventional and Fischer-Tropsch jet fuels. Fuel 2012;98:249-58.

[91] Allen C, Toulson E, Edwards T, Lee T. Application of a novel charge preparation approach to testing the autoignition characteristics of JP-8 and camelina hydroprocessed renewable jet fuel in a rapid compression machine. Combust Flame 2012;159:2780-8.

[92] Zhu Y, Li S, Davidson DF, Hanson RK. Ignition delay times of conventional and alternative fuels behind reflected shock waves. Proc Combust Inst 2015;35(1):241-8.

[93] Valco D, Gentz G, Allen C, Colket M, Edwards T, Gowdagiri S, et al. Autoignition behavior of synthetic alternative jet fuels: An examination of chemical composition effects on ignition delays at low to intermediate temperatures. Proc Combust Inst 2015;35(3):2983-91.

[94] Daniel V, Casey A, Tonghun L. Autoignition behavior of petroleum-based and hydroprocessed renewable jet fuel blends in a rapid compression machine. 51st AIAA Aerospace Sciences Meeting including the New Horizons Forum and Aerospace Exposition, Grapevine 2013. AIAA2013-0896.

[95] Standard Test Method for Determination of Derived Cetane Number (DCN) of Diesel Fuel Oils-Fixed Range Injection Period, Constant Volume Combustion Chamber Method. ASTM D7170; 2012.

[96] Standard Test Method for Determination of Ignition Delay and Derived Cetane Number (DCN) of Diesel Fuel Oils by Combustion in a Constant Volume Chamber. ASTM D6890; 2012. [97] Dooley S, Won SH, Heyne J, Farouk TI, Ju Y, Dryer FL, et al. The experimental evaluation of a methodology for surrogate fuel formulation to emulate gas phase combustion kinetic phenomena. Combust Flame 2012;159:1444-66. 
[98] Dooley S, Won SH, Jahangirian S, Ju Y, Dryer FL, Wang H, et al. The combustion kinetics of a synthetic paraffinic jet aviation fuel and a fundamentally formulated, experimentally validated surrogate fuel. Combust Flame 2012;159:3014-20.

[99] Won SH, Veloo PS, Santner J, Ju Y, Dryer FL. Comparative evaluation of global combustion properties of alternative jet fuels. 51st AIAA Aerospace Sciences Meeting including the New Horizons Forum and Aerospace Exposition, Grapevine 2013. AIAA 2013-0156.

[100] Ghosh P and Jaffe SB. Detailed composition-based model for predicting the cetane number of diesel fuels. Ind Eng Chem Res 2006;45:346-51.

[101] Law CK. Combustion physics: Cambridge University Press; 2006.

[102] Kumar K, Sung CJ, Hui X. Laminar flame speeds and extinction limits of conventional and alternative jet fuels. Fuel 2011;90:1004-11.

[103] Mzé-Ahmed A, Dagaut P, Hadj-Ali K, Dayma G. Oxidation of a coal-to-liquid synthetic jet fuel: experimental and chemical kinetic modeling study. Energ Fuel 2012;26:6070-9.

[104] Kick T, Herbst J, Kathrotia T, Marquetand J, Braun-Unkhoff M, Naumann C, et al. An experimental and modeling study of burning velocities of possible future synthetic jet fuels. Energy 2012;43:111-23.

[105] Vukadinovic V, Habisreuther P, Zarzalis N. Experimental study on combustion characteristics of conventional and alternative liquid fuels. J Eng Gas Turb Power 2012;134:121504.

[106] Hui X and Sung CJ. Laminar flame speeds of transportation-relevant hydrocarbons and jet fuels at elevated temperatures and pressures. Fuel 2013;109:191-200. 
[107] Munzar JD, Zia A, Versailles P, Jimenez R, Akih-Kumgeh B, Bergthorson JM. Comparison of laminar flame speeds, extinction stretch rates and vapor pressures of Jet A-1/HRJ biojet fuel blends. ASME Turbo Expo, Düsseldorf 2014. GT2014-25951.

[108] Ji C, Wang YL, Egolfopoulos FN. Flame studies of conventional and alternative jet fuels. J Propul Power 2011;27:856-63.

[109] Calcote H and Manos D. Effect of molecular structure on incipient soot formation. Combust Flame 1983;49:289-304.

[110] Gill R and Olson D. Estimation of soot thresholds for fuel mixtures. Combust Sci Technol 1984;40:307-15.

[111] Yang Y, Boehman AL, Santoro RJ. A study of jet fuel sooting tendency using the threshold sooting index (TSI) model. Combust Flame 2007;149:191-205.

[112] Stouffer SD, Pawlik R, Justinger G, Heyne J, Zelina J, Ballal D. Combustion performance and emissions characteristics for a well stirred reactor for low volatility hydrocarbon fuels. 43rd AIAA/ASME/SAE/ASEE Joint Propulsion Conference \& Exhibit, Cincinnati 2007. AIAA20075663.

[113] Naik CV, Puduppakkam KV, Modak A, Meeks E, Wang YL, Feng Q, et al. Detailed chemical kinetic mechanism for surrogates of alternative jet fuels. Combust Flame 2011;158:434-45.

[114] Mzé-Ahmed A, Hadj-Ali K, Dievart P, Dagaut P. Kinetics of oxidation of a synthetic jet fuel in a jet-stirred reactor: experimental and modeling study. Energ Fuel 2010;24:4904-11.

[115] Dagaut P, Karsenty F, Dayma G, Diévart P, Hadj-Ali K, Mzé-Ahmed A, et al. Experimental and detailed kinetic model for the oxidation of a Gas to Liquid $(\mathrm{GtL})$ jet fuel. Combust Flame 2014;161:835-47. 
[116] Edwards T and Maurice LQ. Surrogate mixtures to represent complex aviation and rocket fuels. J Propul Power 2001;17:461-6.

[117] Colket M, Edwards T, Williams S, Cernansky NP, Miller DL, Egolfopoulos F, et al. Development of an experimental database and kinetic models for surrogate jet fuels. 45th AIAA Aerospace Sciences Meeting and Exhibit, Cincinnati 2007. AIAA2007-770

[118] Violi A, Yan S, Eddings E, Sarofim A, Granata S, Faravelli T, et al. Experimental formulation and kinetic model for JP-8 surrogate mixtures. Combust Sci Technol 2002;174:399417.

[119] Dryer FL, Jahangirian S, Dooley S, Won SH, Heyne JS, Iyer VR, et al. Emulating the combustion behavior of real jet aviation fuels by surrogate mixtures of hydrocarbon fluid blends: implications for science and engineering. Energ Fuel 2014;28(5):3474-85.

[120] Kim D, Martz J, Violi A. A surrogate for emulating the physical and chemical properties of conventional jet fuel. Combust Flame 2014;161(6):1489-98.

[121] Huber ML, Smith BL, Ott LS, Bruno TJ. Surrogate mixture model for the thermophysical properties of synthetic aviation fuel S-8: Explicit application of the advanced distillation curve. Energ Fuel 2008;22:1104-14.

[122] Huber M, Bruno T, Chirico R, Diky V, Kazakov A, Lemmon E, et al. Equations of state on demand: application for surrogate fuel development. Int J Thermophys 2011;32:596-613.

[123] Mawid MA. Development of a detailed chemical kinetic mechanism for mixtures of JP-8 fuel and Fischer-Tropsch-Based synthetic jet fuel. 43rd AIAA/ASME/SAE/ASEE Joint Propulsion Conference and Exhibit, Cincinnati 2007. AIAA2007-5668.

[124] Slavinskaya NA, Zizin A, Aigner M. On model design of a surrogate fuel formulation. J Eng Gas Turb Power 2010;132:111501. 
[125] Bruno TJ and Smith BL. Improvements in the measurement of distillation curves. 2. Application to aerospace/aviation fuels RP-1 and S-8. Ind Eng Chem Res 2006;45:4381-8.

[126] Frenkel M, Chirico R, Diky V, Muzny C, Lemmon E, Yan X, et al. NIST ThermoData Engine. NIST Standard Reference Database 103b, Version. 2008;5. 


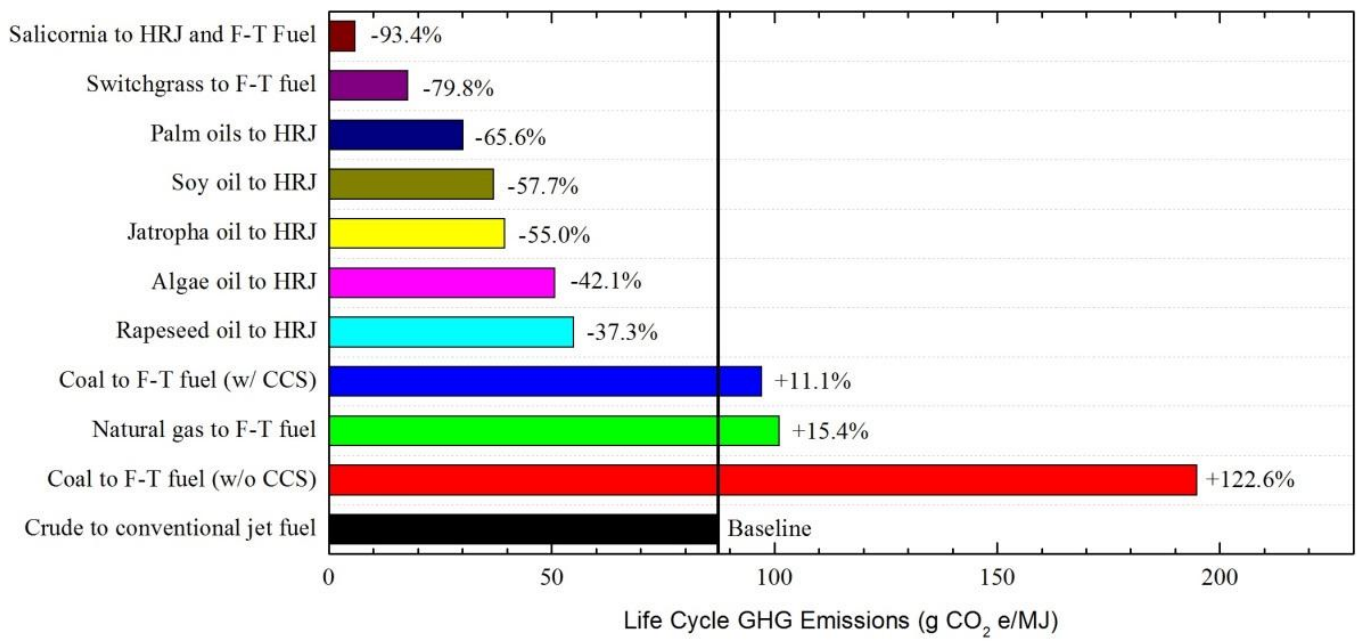

Figure 1 - Life-cycle greenhouse gas emissions for conventional and alternative jet fuels. The units of ' $\mathrm{g} \mathrm{CO}_{2}$ e/MJ' represent the $\mathrm{CO}_{2}$ equivalent emissions per unit of energy [11]. 


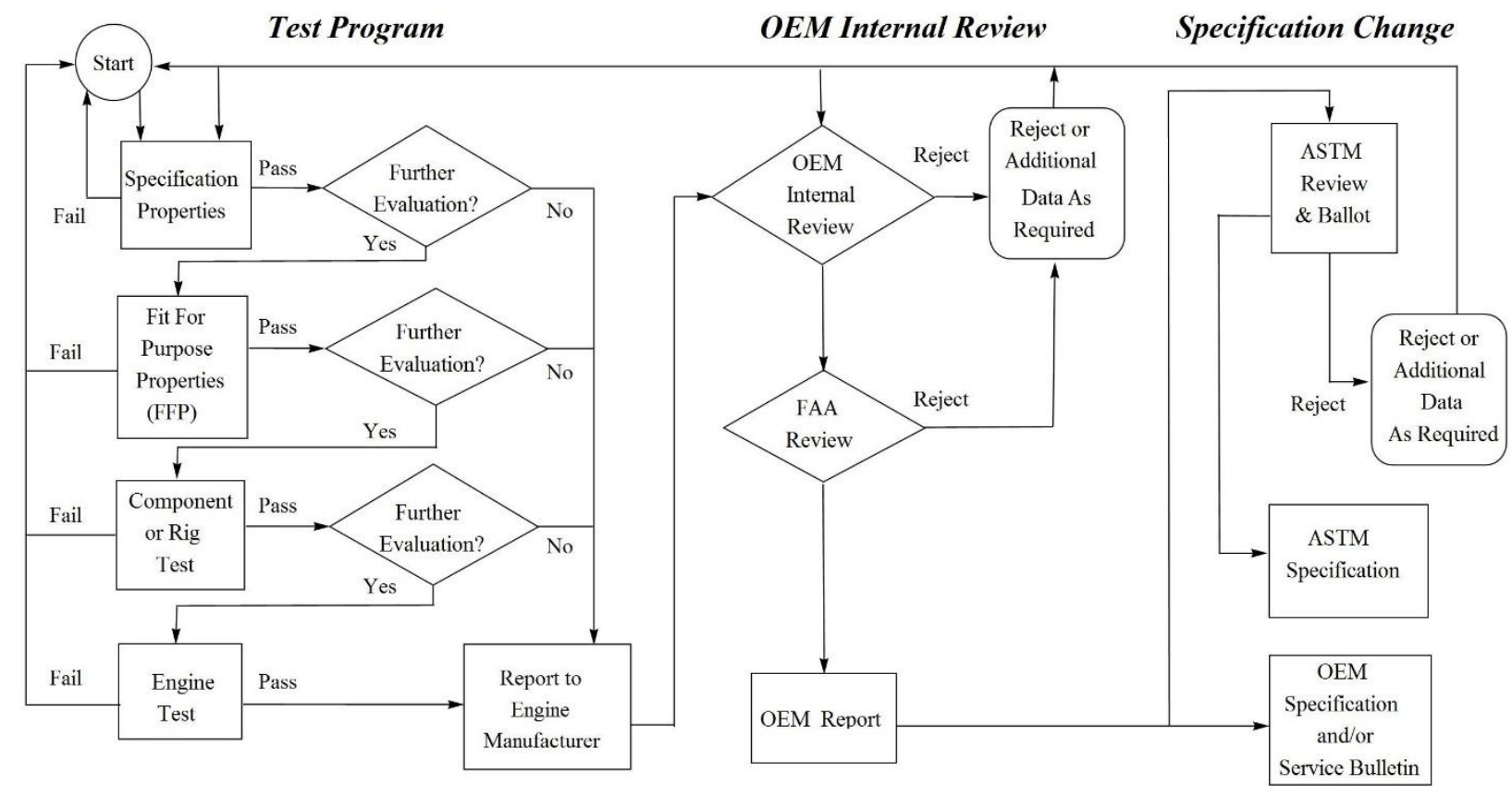

Figure 2 - Overview of fuel and additive approval process [46]. 


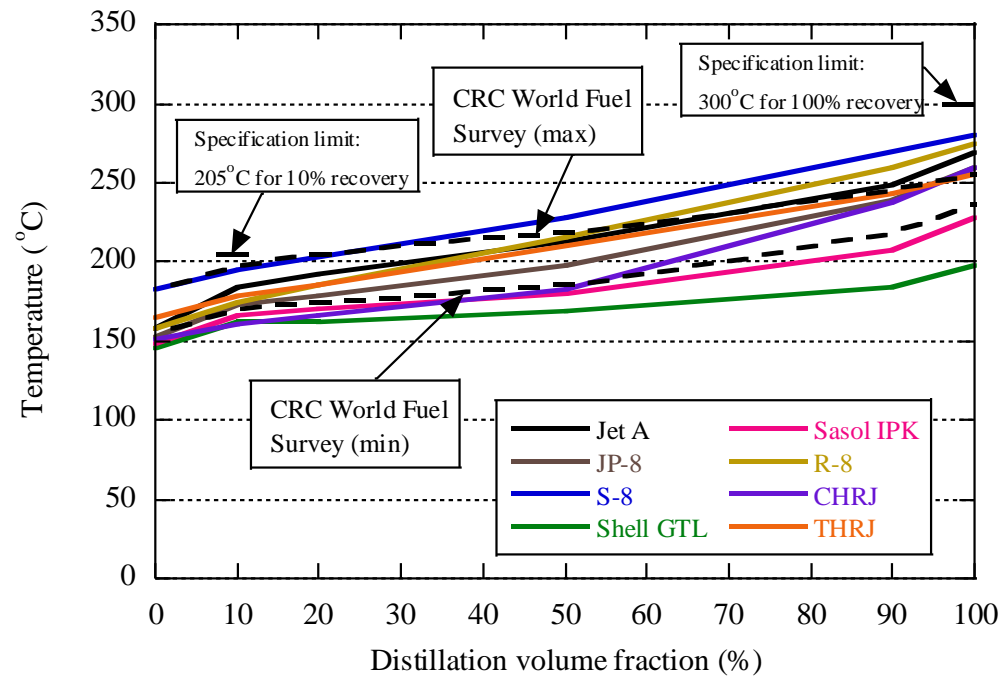

Figure 1 - Distillation curves of conventional and alternative jet fuels. Data were taken from Refs. $[13,51,56]$. 

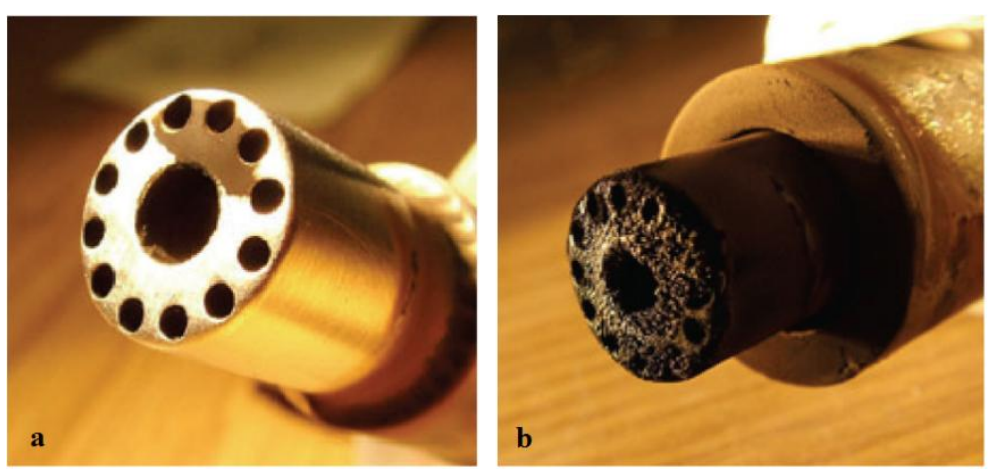

Figure 2 - Igniter deposits: (a) 100\% synthetic fuel and (b) Jet A-1 [50] (Courtesy: G. Pucher). 


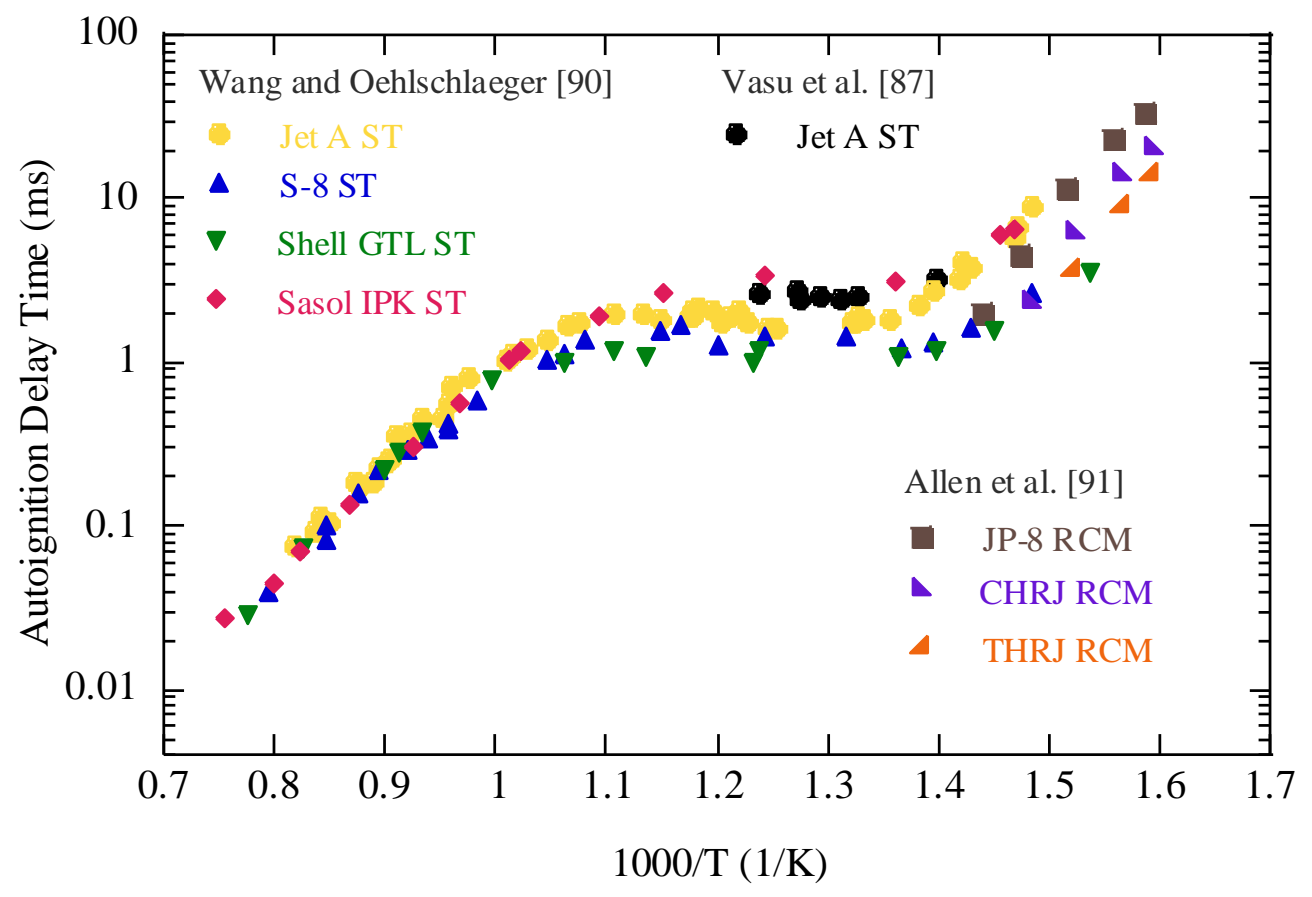

Figure 4 - Autoignition delay times of various stoichiometric jet fuel/air mixtures at a pressure of $20 \mathrm{~atm}$ measured in two shock tubes (STs) and a rapid compression machine (RCM). Data are from Refs. [87,90,91]. 


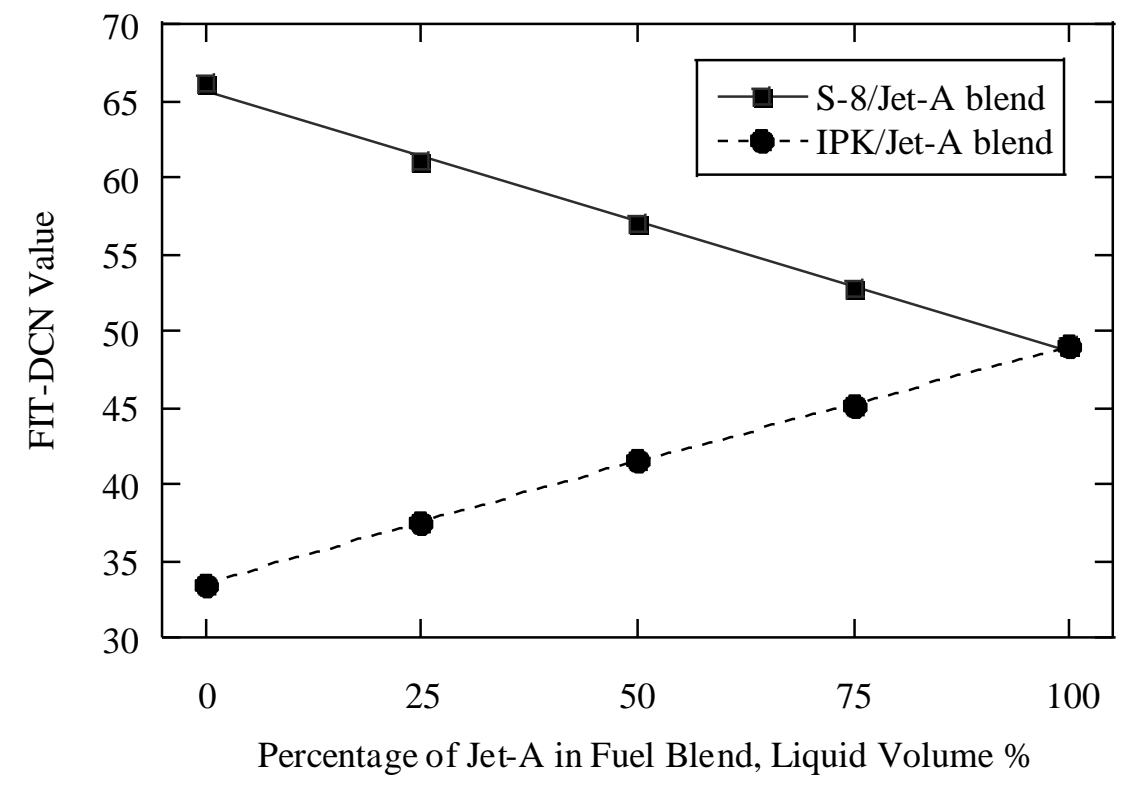

Figure 5 - FIT-DCN values of binary blends of conventional and alternative jet fuels [53]. 


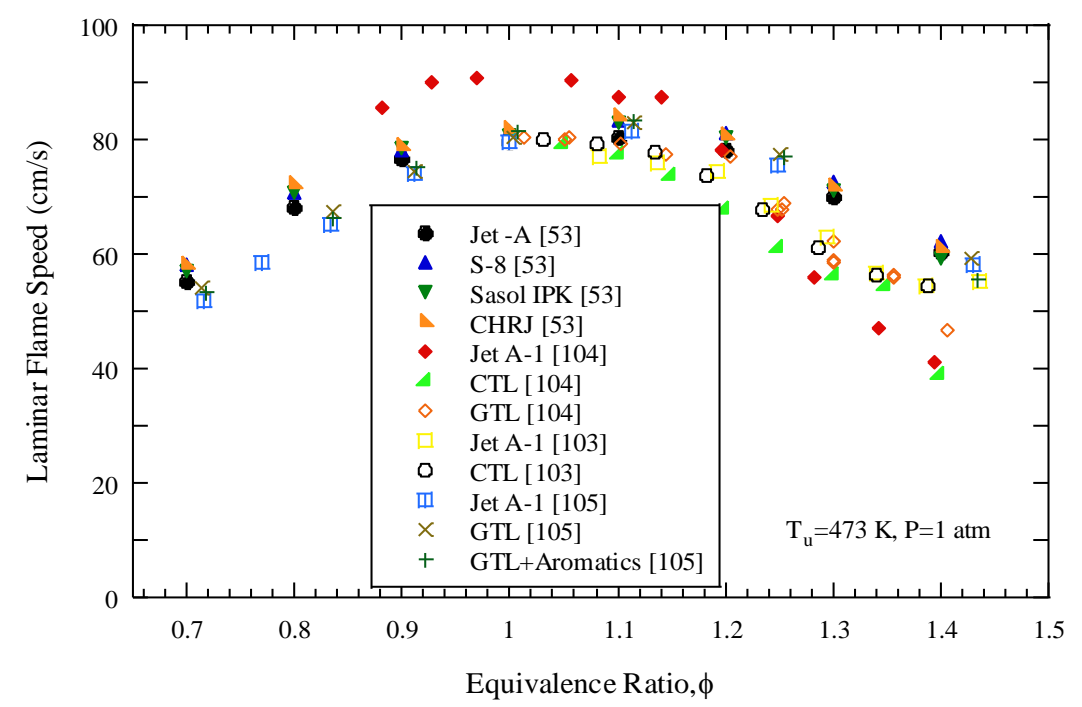

Figure 6 - Laminar flame speeds of various jet fuel/air mixtures at preheat temperature of about $\mathrm{T}_{\mathrm{u}}=473 \mathrm{~K}$ and pressure of $\mathrm{P}=1 \mathrm{~atm}$. Data were taken from Refs. [53,103-105]. 


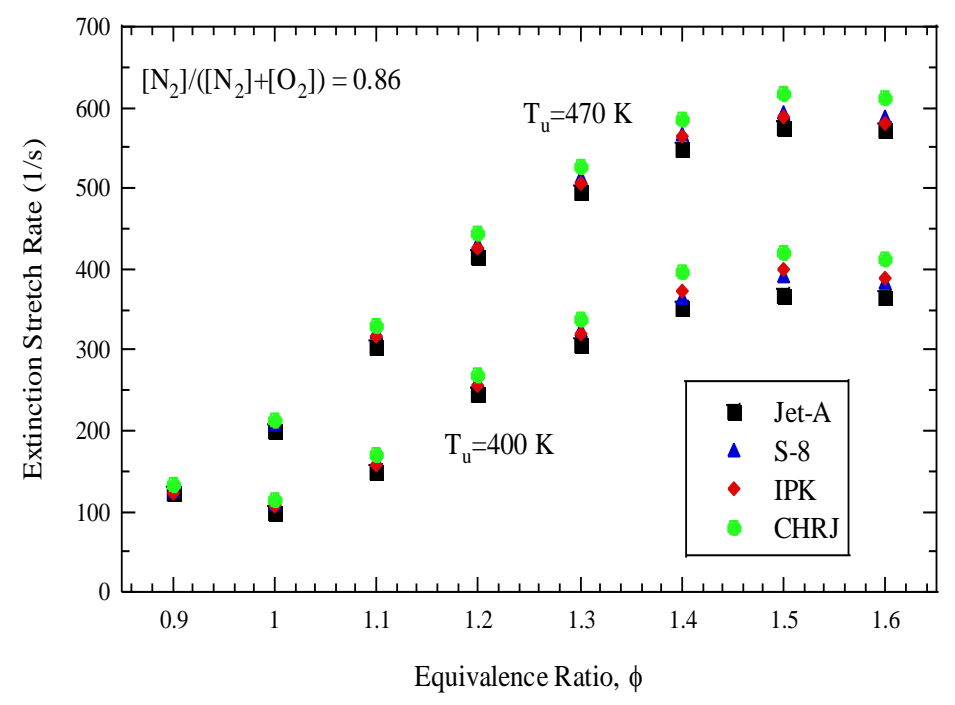

Figure 7 - Extinction strain rates of Jet A/oxidizer, S-8/oxidizer, IPK/oxidizer, and CHRJ/oxidizer at $400 \mathrm{~K}$ and $470 \mathrm{~K}$ preheat temperatures as a function of equivalence ratio [53]. 


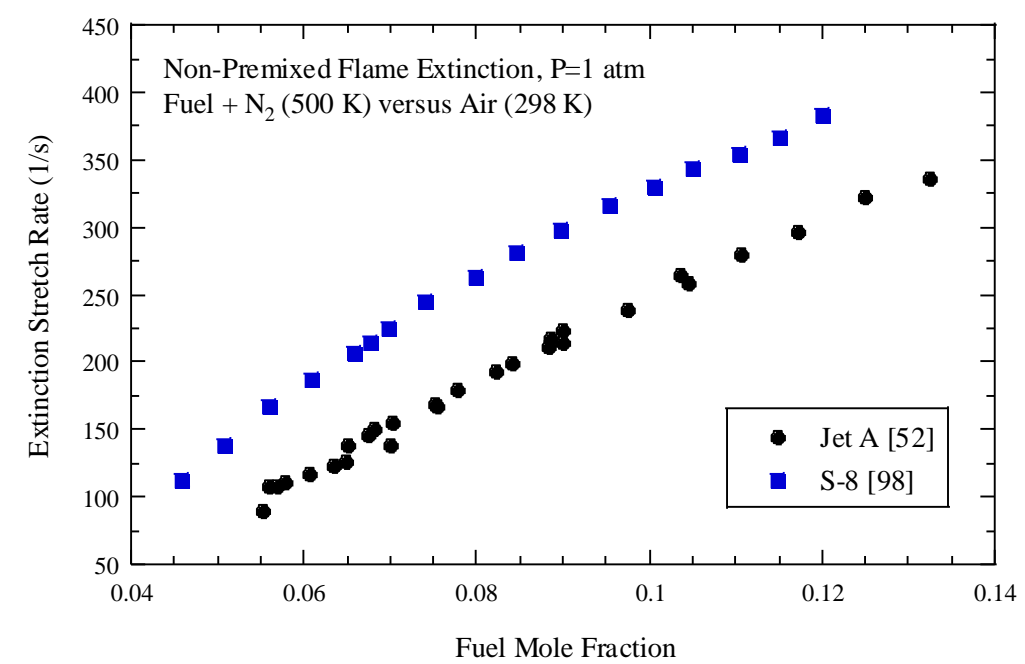

Figure 8 - Extinction strain rates of Jet A [52] and S-8 [98] in atmospheric non-premixed flames with fuel/ $\mathrm{N}_{2}$ temperature of $500 \mathrm{~K}$ and air temperature of $298 \mathrm{~K}$. 


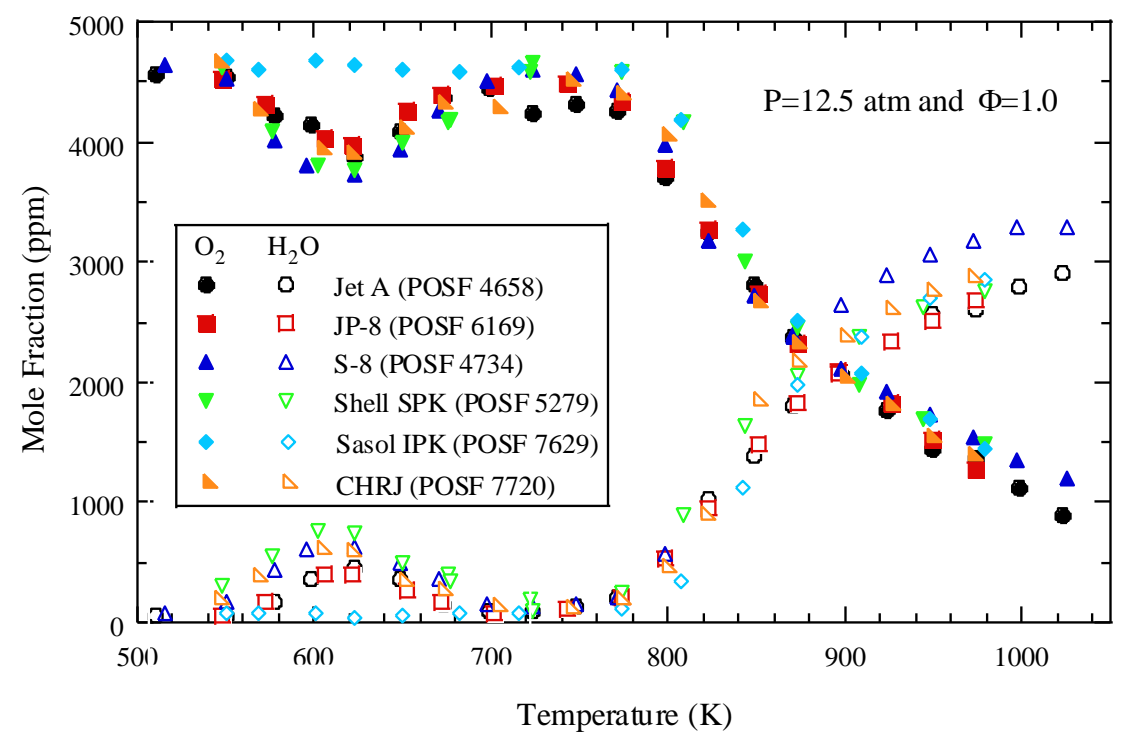

Figure 9 - Comparison of species data from flow reactor oxidation of conventional and alternative jet fuels [99]. 
Table 1 - ASTM standard and properties of conventional and alternative jet fuels.

\begin{tabular}{|c|c|c|c|c|c|c|c|c|c|}
\hline Property & $\begin{array}{c}\text { ASTM } \\
\text { standard }\end{array}$ & Jet A & JP-8 & S-8 & $\begin{array}{c}\text { Shell } \\
\text { GTL }^{\circledR} \\
\end{array}$ & $\begin{array}{l}\text { Sasol } \\
\text { IPK }^{\circledR} \\
\end{array}$ & $\mathrm{R}-8$ & CHRJ & THRJ \\
\hline POSF number & -- & 4658 & 3773 & 4734 & 5172 & 5642 & 5469 & 6152 & 6308 \\
\hline \multicolumn{10}{|l|}{ Composition } \\
\hline n-paraffins, $\% \mathrm{wt}$ & -- & 28 & 19 & 17.7 & 53.3 & 2.1 & 13.1 & 10.2 & 8.8 \\
\hline iso-paraffins, $\% \mathrm{wt}$ & -- & 29 & 38.2 & 82 & 45.7 & 88 & -- & 78.9 & 89.4 \\
\hline cyclo-paraffins, $\%$ wt & -- & 20 & 24.1 & $<0.4$ & $<1.0$ & 9 & -- & 11.1 & 2.1 \\
\hline aromatics, $\% \mathrm{wt}$ & Report & 20 & 13.5 & $<0.1$ & $<0.2$ & $<0.5$ & -- & $<0.2$ & $<0.4$ \\
\hline total sulfur, $\%$ wt & $\max 0.3$ & -- & 0.0064 & $\begin{array}{c}<0.00 \\
1 \\
\end{array}$ & $<0.001$ & $<0.001$ & $<0.001$ & $<0.0018$ & $<0.003$ \\
\hline \multicolumn{10}{|l|}{ Distillation } \\
\hline initial boiling point, ${ }^{\circ} \mathrm{C}$ & Report & 158 & 152 & 182 & 146 & 149 & 158 & 151 & 165 \\
\hline $10 \%$ recovered, ${ }^{\circ} \mathrm{C}$ & $\max 205$ & 184 & 173 & 195 & 162 & 166 & 175 & 161 & 179 \\
\hline $20 \%$ recovered, ${ }^{\circ} \mathrm{C}$ & Report & 192 & 179 & -- & 162 & 170 & 185 & 166 & 185 \\
\hline $50 \%$ recovered, ${ }^{\circ} \mathrm{C}$ & Report & 213 & 198 & 228 & 169 & 180 & 215 & 182 & 210 \\
\hline $90 \%$ recovered, ${ }^{\circ} \mathrm{C}$ & Report & 248 & 239 & -- & 184 & 208 & 260 & 237 & 243 \\
\hline final boiling point, ${ }^{\circ} \mathrm{C}$ & $\max 300$ & 269 & 260 & 280 & 198 & 228 & 274 & 259 & 255 \\
\hline Flash point, ${ }^{\circ} \mathrm{C}$ & $\min 38$ & 47 & 48 & 49 & 44 & 44 & 48 & 43 & 55 \\
\hline Freezing point, ${ }^{\circ} \mathrm{C}$ & $\max -47$ & -49 & -49 & -59 & -54 & $<-78$ & -49 & $<-77$ & -62 \\
\hline Density@15² $\mathrm{Cg} / \mathrm{m}^{3}$ & $775-840$ & 806 & 790 & 757 & 737 & 762 & 762 & 751 & 758 \\
\hline Viscosity@-20C, cSt & $\max 8.0$ & 5.2 & 4.1 & 4.6 & 2.6 & 3.6 & 5.5 & 3.3 & 5.3 \\
\hline $\begin{array}{l}\text { Neat heat of combustion, } \\
\mathrm{MJ} / \mathrm{kg}\end{array}$ & $\min 42.8$ & 42.8 & 43 & 44.1 & 44.2 & 44 & 44.1 & 44.3 & 44.1 \\
\hline Smoke point, $\mathrm{mm}$ & $\min 19.0$ & 21 & 25 & $>43$ & 40 & $>40$ & $>40$ & 50 & $>40$ \\
\hline $\mathrm{H} / \mathrm{C}$ molar ratio & -- & 1.957 & 1.937 & 2.152 & 2.202 & 2.119 & 2.152 & 2.169 & 2.152 \\
\hline Molecular weight, $\mathrm{g} / \mathrm{mol}$ & -- & 142 & 153 & 168 & 146 & 156 & 177 & 160 & 174 \\
\hline
\end{tabular}

Data were taken from Refs. [13,42,51-53]

"Report" - The product of the test program that formally documents all data and information compiled during the evaluation process. 
Table 2 - Combustor component tests for alternative jet fuels.

\begin{tabular}{|c|c|c|}
\hline $\begin{array}{l}\text { Performance } \\
\text { targets }\end{array}$ & Testing components & Testing fuel \\
\hline \multirow{2}{*}{ Atomization } & Auxiliary power units (APUs) atomizer (2007) [58] & Sasol FSJF ${ }^{\circledR}$ \\
\hline & Pressure-swirl atomizer $(2012,2014,2015)[59,60,61]$ & FT CTL, GTL, HRJ \\
\hline \multirow{6}{*}{$\begin{array}{l}\text { Ignition and } \\
\text { altitude relight }\end{array}$} & Full-annular Trent combustor (2007) [62] & Sasol FSJF ${ }^{\circledR}$ \\
\hline & Annular-can combustor sector (2012) [63] & Shell GTL ${ }^{\circledR}$ \\
\hline & Twin-sector combustor $(2011)[64,66]$ & FT SPKs \\
\hline & Single can-type combustor (2005) [65] & FT SPK \\
\hline & Single cup rectangular combustor (2012) [59] & FT CTL \\
\hline & RQL combustor (2014) [67] & SPK \\
\hline \multirow{5}{*}{ Lean blowout } & Full-scale annular combustor (2007) [58] & Sasol FSJF ${ }^{\circledR}$ \\
\hline & Three-cup combustor sector (2010) [68] & Shell GTL ${ }^{\circledR}$ \\
\hline & Single cup rectangular combustor (2012) [59] & FT CTL \\
\hline & Heterogeneous combustor (2012) [69] & $\begin{array}{c}\text { Sasol FSJF }{ }^{\circledR}, \text { GTL, } \\
\text { SPK }\end{array}$ \\
\hline & RQL combustor (2014) [67] & SPK \\
\hline \multirow{6}{*}{$\begin{array}{l}\text { Emissions, } \\
\text { smoke, and } \\
\text { carbon deposit }\end{array}$} & Four-nozzle arc combustor sector (2007) [70] & Sasol FSJF ${ }^{\circledR}$ \\
\hline & Single can-type combustor (2005) [65] & FT SPK \\
\hline & Three-cup combustor sector (2010) [68] & Shell GTL ${ }^{\circledR}$ \\
\hline & Twin-sector combustor (2011) [66] & FT SPKs \\
\hline & Single cup rectangular combustor (2012) [59] & FT CTL \\
\hline & Can-annular combustor $(2011,2013)[71,72]$ & $\begin{array}{c}\text { CTL, GTL, HRJ, } \\
\text { FAME }\end{array}$ \\
\hline
\end{tabular}

Sources: Refs. [58-72] 
Table 3 - Derived cetane numbers of conventional and alternative jet fuels.

\begin{tabular}{|c|c|c|c|}
\hline \multicolumn{2}{|c|}{ Fuel } & \multicolumn{2}{|c|}{$\mathrm{DCN}$} \\
\hline Name & POSF\# & FIT, ASTM D7170 & $\begin{array}{c}\text { IQT, ASTM } \\
\text { D6890 }\end{array}$ \\
\hline Jet A & 4658 & $49.35[53]$ & $47.1[97]$ \\
\hline JP-8 & 6169 & - & $47.3[99]$ \\
\hline Syntroleum S-8 ${ }^{\circledR}$ & 4734 & $66.50[53]$ & $58.7[98]$ \\
\hline Shell GTL ${ }^{\circledR}$ & 5172 & $64.69[53]$ & $59.1[57]$ \\
\hline Shell SPK ${ }^{\circledR}$ & 5729 & - & 58.4 [99] \\
\hline Sasol IPK $^{\circledR}$ & 5642 & 33.46 [53] & 31.28 [57] \\
\hline Sasol IPK $^{\circledR}$ & 7629 & - & 31.1 [99] \\
\hline $\mathrm{R}-8$ & 5469 & $66.27[53]$ & - \\
\hline Camelina HRJ & 6152 & $60.70[53]$ & $53.94[57]$ \\
\hline Camelina HRJ & 7720 & - & 58.9 [99] \\
\hline Tallow HRJ & 6308 & $65.85[53]$ & $58.1[99]$ \\
\hline
\end{tabular}

Data were taken from Refs. [53,57,97-99] 
Table 4 - Threshold sooting indices of conventional and alternative jet fuels.

\begin{tabular}{|c|c|c|}
\hline \multicolumn{2}{|c|}{ Fuel } & \multirow{2}{*}{ TSI } \\
\hline Name & POSF\# & \\
\hline Jet A & 4658 & 21.4 [97] \\
\hline JP-8 & 6169 & 19.28 [99] \\
\hline Shell SPK ${ }^{\circledR}$ & 5729 & 9.11 [99] \\
\hline Sasol IPK ${ }^{\circledR}$ & 7629 & 17.28 [99] \\
\hline Camelina HRJ & 7720 & 11.99 [99] \\
\hline Tallow HRJ & 6308 & 11.58 [99] \\
\hline
\end{tabular}

Data were taken from Refs. [97,99] 
Table 5 - Surrogates for various alternative jet fuels.

\begin{tabular}{|c|c|c|c|}
\hline Reference & $\begin{array}{l}\text { Target } \\
\text { real fuel }\end{array}$ & Surrogate fuel & Validation targets \\
\hline $\begin{array}{l}\text { Huber et al. } \\
{[121]}\end{array}$ & S-8 & $\begin{array}{c}\text { n-nonane/2,6-dimethyloctane/ } \\
\text { 3-methyldecane/n-tridecane/n-tetradecane/ } \\
\text { n-pentadecane/n-hexadecane } \\
0.03 / 0.28 / 0.34 / 0.13 / 0.20 / 0.015 / 0.005 \text { (by mole) }\end{array}$ & $\begin{array}{l}\text { Density, thermal conductivity, } \\
\text { sound speed, viscosity, } \\
\text { distillation curve }\end{array}$ \\
\hline $\begin{array}{l}\text { Huber et al. } \\
{[122]}\end{array}$ & Bio-SPK & $\begin{array}{c}\text { 4-methyloctane/2,5-dimethylnonane/ } \\
\text { 2,3,5-trimethyldecane/n-tridecane/ } \\
\text { n-pentadecane } \\
0.105 / 0.281 / 0.164 / 0.227 / 0.223 \text { (by mole) }\end{array}$ & Distillation curve \\
\hline $\begin{array}{l}\text { Mawid et al. } \\
{[123]}\end{array}$ & S-8 & $\begin{array}{c}\text { n-decane/iso-octane } \\
0.60 / 0.40 \text { (by volume) }\end{array}$ & $\begin{array}{l}\text { Autoignition delay time and } \\
\text { species profile }\end{array}$ \\
\hline \multirow{2}{*}{$\begin{array}{l}\text { Naik et al. } \\
{[113]}\end{array}$} & S-8 & $\begin{array}{c}\text { iso-octane } / \text { n-decane } / \text {-dodecane } \\
0.32 / 0.25 / 0.43 \text { (by mole) }\end{array}$ & \multirow{2}{*}{$\begin{array}{l}\text { Laminar flame speed, } \\
\text { extinction strain rate, } \mathrm{NO}_{\mathrm{x}}\end{array}$} \\
\hline & $\begin{array}{l}\text { Shell } \\
\text { GTL }^{\circledR}\end{array}$ & $\begin{array}{c}\text { iso-octane } / \text {-decane/n-dodecane } \\
0.28 / 0.61 / 0.11 \text { (by mole) }\end{array}$ & \\
\hline $\begin{array}{l}\text { Dooley et al. } \\
{[98]}\end{array}$ & S-8 & $\begin{array}{l}\text { n-dodecane/iso-octane } \\
0.519 / 0.481 \text { (by mole) }\end{array}$ & $\begin{array}{l}\text { Species profile, autoignition } \\
\text { delay time, extinction strain } \\
\text { rate }\end{array}$ \\
\hline \multirow{3}{*}{$\begin{array}{l}\text { Slavinskaya } \\
\text { et al. [124] }\end{array}$} & \multirow{3}{*}{ GTL } & $\begin{array}{c}\text { propyl-cyclohexane/2,7-dimethyloctane/ } \\
\text { 2-methyldecane/n-decane } \\
0.15 / 0.17 / 0.32 / 0.36 \text { (by volume) }\end{array}$ & Physical properties \\
\hline & & $\begin{array}{c}\text { propyl-cyclohexane/n-decane/iso-octane } \\
0.15 / 0.36 / 0.49 \text { (by volume) }\end{array}$ & \multirow[b]{2}{*}{ Autoignition delay time } \\
\hline & & $\begin{array}{c}\text { propyl-cyclohexane/n-decane/ } \\
\text { 2-methyldecane/iso-octane } \\
0.15 / 0.36 / 0.32 / 0.17 \text { (by volume) } \\
\end{array}$ & \\
\hline $\begin{array}{l}\text { Mzé-Ahmed } \\
\text { et al. [114] }\end{array}$ & CTL & $\begin{array}{c}\text { n-decane/iso-octane/ } \\
\text { n-propylcyclohexane/ } \\
\text { n-propylbenzene } \\
0.395 / 0.130 / 0.373 / 0.102 \text { (by mole) }\end{array}$ & $\begin{array}{l}\text { Species profile, autoignition } \\
\text { delay time, laminar flame speed }\end{array}$ \\
\hline \multirow{2}{*}{$\begin{array}{l}\text { Dagaut et al } \\
{[115]}\end{array}$} & \multirow{2}{*}{ GTL } & $\begin{array}{c}\text { n-decane/iso-octane/n-propylcyclohexane } \\
0.577 / 0.332 / 0.091 \text { (by mole) }\end{array}$ & \multirow{2}{*}{$\begin{array}{c}\text { Species profile, autoignition } \\
\text { delay time, laminar flame speed }\end{array}$} \\
\hline & & $\begin{array}{c}\text { n-decane/iso-octane/n-propylcyclohexane } \\
0.699 / 0.214 / 0.087 \text { (by mole) }\end{array}$ & \\
\hline
\end{tabular}

Sources: Refs. [98,113-115,121-124] 